\title{
Unique adaptations in neonatal hepatic transcriptome, nutrient signaling, and one- carbon metabolism in response to feeding ethyl cellulose rumen-protected methionine during late-gestation in Holstein cows
}

Valentino Palombo ${ }^{1,2}$, Abdulrahman Alharthi ${ }^{2,3}$, Fernanda Batistel ${ }^{4}$, Claudia Parys $^{5}$, Jessie Guyader ${ }^{5}$, Erminio Trevisi ${ }^{6}$, Mariasilvia D'Andrea' and Juan J. Loor ${ }^{2 *}$

\begin{abstract}
Background: Methionine (Met) supply during late-pregnancy enhances fetal development in utero and leads to greater rates of growth during the neonatal period. Due to its central role in coordinating nutrient and one-carbon metabolism along with immune responses of the newborn, the liver could be a key target of the programming effects induced by dietary methyl donors such as Met. To address this hypothesis, liver biopsies from 4-day old calves ( $n=6 /$ group) born to Holstein cows fed a control or the control plus ethyl-cellulose rumen-protected Met for the last 28 days prepartum were used for DNA methylation, transcriptome, metabolome, proteome, and one-carbon metabolism enzyme activities.

Results: Although greater withers and hip height at birth in Met calves indicated better development in utero, there were no differences in plasma systemic physiological indicators. RNA-seq along with bioinformatics and transcription factor regulator analyses revealed broad alterations in 'Glucose metabolism', 'Lipid metabolism, 'Glutathione', and 'Immune System' metabolism due to enhanced maternal Met supply. Greater insulin sensitivity assessed via proteomics, and efficiency of transsulfuration pathway activity suggested beneficial effects on nutrient metabolism and metabolic-related stress. Maternal Met supply contributed to greater phosphatidylcholine synthesis in calf liver, with a role in very low density lipoprotein secretion as a mechanism to balance metabolic fates of fatty acids arising from the diet or adipose-depot lipolysis. Despite a lack of effect on hepatic amino acid (AA) transport, a reduction in metabolism of essential AA within the liver indicated an AA 'sparing effect' induced by maternal Met.

* Correspondence: jloor@illinois.edu

2Department of Animal Sciences and Division of Nutritional Sciences, University of Illinois, Urbana, IL 61801, USA

Full list of author information is available at the end of the article

C The Author(s). 2021 Open Access This article is licensed under a Creative Commons Attribution 4.0 International License, which permits use, sharing, adaptation, distribution and reproduction in any medium or format, as long as you give appropriate credit to the original author(s) and the source, provide a link to the Creative Commons licence, and indicate if changes were made. The images or other third party material in this article are included in the article's Creative Commons licence, unless indicated otherwise in a credit line to the material. If material is not included in the article's Creative Commons licence and your intended use is not permitted by statutory regulation or exceeds the permitted use, you will need to obtain permission directly from the copyright holder. To view a copy of this licence, visit http://creativecommons.org/licenses/by/4.0/ The Creative Commons Public Domain Dedication waiver (http://creativecommons.org/publicdomain/zero/1.0/) applies to the data made available in this article, unless otherwise stated in a credit line to the data. 


\begin{abstract}
(Continued from previous page)
Conclusions: Despite greater global DNA methylation, maternal Met supply resulted in distinct alterations of hepatic transcriptome, proteome, and metabolome profiles after birth. Data underscored an effect on maintenance of calf hepatic Met homeostasis, glutathione, phosphatidylcholine and taurine synthesis along with greater efficiency of nutrient metabolism and immune responses. Transcription regulators such as FOXO1, PPARG, E2F1, and CREB1 appeared central in the coordination of effects induced by maternal Met. Overall, maternal Met supply induced better immunometabolic status of the newborn liver, conferring the calf a physiologic advantage during a period of metabolic stress and suboptimal immunocompetence.
\end{abstract}

Keywords: Calf, Epigenetics, Methyl donor, Nutritional programming

\section{Background}

Maternal nutrient and metabolic stresses during pregnancy are important factors that can affect fetal and neonatal growth, development [1, 2], as well as metabolic and inflammatory responses of the offspring [3]. In dairy cattle, the last two months of gestation are the mostcritical period for calf fetal growth, since most of the muscle and adipose tissue formation takes place primarily during this time. Around parturition, due to normal decreases in feed intake, cows are exposed to negative energy and essential amino acid (AA) balance, hence, AA such as methionine (Met) become limiting for both cow, fetus, and/or new-born calf $[4,5]$.

In addition to being a substrate for protein synthesis, Met is a key component of one-carbon metabolism [6] where it is initially converted into S-adenosylmethionine (SAM), the major biological methyl donor [7] and where it is involved, through the transsulfuration pathway, in the synthesis of antioxidants glutathione (GSH) and taurine $[8,9]$. Physiologically, animals not only obtain Met from the diet, but also from protein breakdown and remethylation of homocysteine in the Met cycle [10]. Through synthesis of SAM, methyl donors may alter gene transcription in the offspring by methylating DNA and RNA [11, 12]. In non-ruminants, it was demonstrated that maternal methyl donor supplementation (i.e. betaine) led to epigenetic changes that increased expression of genes controlling hepatic gluconeogenesis in the neonate $[13,14]$.

Epigenetic control of gene expression, also induced by the intrauterine environment, is one of the underlying mechanisms of the 'Fetal programming' hypothesis [15, 16] that was first proposed by Barker in 1998 [17]. This concept seeks to explain the effect of maternal nutrition on long-term offspring growth and health [18, 19]; despite its importance, few studies in dairy cattle have addressed the role of nutrient manipulation during lategestation on fetal and postnatal development. In this regard, for example, Met supplementation is long recognized in dairy cattle as an effective approach to improve productive performance $[20,21]$, but only recently a promising path in research related to the maternal effect of Met supply on calf health, immune function, and reproductive performance has been highlighted [22]. In particular, it was recently demonstrated that rumenprotected Met (RPM) supplementation during the periparturient period enhanced dry matter intake (DMI) leading to reduced incidence of metabolic disorders and improved overall cow health [23, 24]. Furthermore, enhancing Met supply during late-pregnancy upregulated mRNA abundance of AA and glucose transporters in cow placenta [25], and was also associated with changes in hepatic one-carbon metabolism and transsulfuration in calf liver [26]. Although the greater DM intake during the last 2-3 wk. prior to parturition that has been consistently reported in cows fed RPM could explain a portion of the greater body mass of the calves at birth [25, 26], other mechanisms potentially encompassing nutrient assimilation efficiency likely play a role.

There are strong associations between Met supplementation during late-pregnancy and body weight and immune response in calves [27], confirming evidence that AA can affect regulation of metabolic pathways to sustain the immune response against pathogens [28]. The potential role of methyl donors in the early-life innate immune response was recently reported in calves born to cows with high body condition score and after ex vivo lipopolysaccharide challenge [29]. Furthermore, single gene expression studies have suggested that enhancing maternal supply of Met could promote the calf's ability to quickly adapt to extrauterine life $[10,30,31]$. Lastly, Met supplementation as RPM altered the transcriptome of bovine preimplantation embryos harvested at 70 days postpartum [32]. Although these findings provided some evidence that methyl donors could play a role in nutritional programming in dairy cows, knowledge of the underlying mechanisms between lategestation methyl donor supply and fetal programing in dairy cattle is still in its infancy.

Since nutritional management of modern dairy cows entails dietary manipulation of energy density and nutrients such as essential AA during the last stages of gestation ( 4-6 weeks prepartum) [9], a deeper investigation of the biological outcomes on the neonatal calf is 
warranted. Particularly considering possible contributions of maternal nutrition to the calf's immune and sanitary challenges during their first weeks of life [33]. In this context, the use of RNA sequencing technology (RNA-Seq) has already proven to be a promising tool in helping us detect offspring genome-wide alterations in response to maternal post-ruminal Met supply [32].

In the present work, a subset of calves from a larger cohort $[24,27]$ was used to investigate the effect of maternal post-ruminal Met supply during late-pregnancy $(-28 \pm 2 \mathrm{~d}$ to parturition) on changes in plasma systemic physiological indicators, transcriptome profiles, DNA methylation, one-carbon metabolism enzyme activities and protein abundance of nutrient-sensing pathways in the liver of new-born calves. Our general hypothesis was that Met supplementation as RPM during late-gestation improves liver immunometabolic functions in the offspring similar to those observed in the cow [34], in particular affecting key metabolic and immunological pathways such as one-carbon metabolism and transsulfuration reactions.

\section{Results}

Growth performance, blood biomarkers and AA concentrations in plasma

At birth, calves born to dams fed MET had greater hip height $(P$ value $=0.04)$ and wither height $(P$ value $=0.01$. No significant differences were detected for body weight and length, and hip width $(P$ value $\geq 0.10)$ (Table 1$)$. Calves in MET (from cows fed additional Met) had a tendency for lower concentration of glucose compared with CON (control) calves $(P$ value $=0.08)$ at day 2 , whereas no significant differences were detected for other blood parameters (Table 2). In this regards, it is interesting to note that no significant differences were detected for insulin concentrations (Table 2). At day 2, there was no significant effect of maternal diet for any AA concentration in the plasma; however, there was a tendency for higher concentrations of Phenylalanine

Table 1 Developmental parameters at birth in Holstein calves ( $n=6 /$ group) born to cows randomly assigned to receive a basal control (CON) diet from $-28 \pm 2$ d to parturition [1.47 $\mathrm{Mcal} / \mathrm{kg}$ dry matter (DM) and $15.3 \%$ crude protein (CP)] with no added Met or CON plus ethyl cellulose Met (MET, Mepron ${ }^{\oplus}$, Evonik Nutrition \& Care GmbH, Germany)

\begin{tabular}{lllll}
\hline Item & \multicolumn{2}{l}{ Maternal diet } & SEM & $\begin{array}{l}\boldsymbol{p} \text { - } \\
\text { value }\end{array}$ \\
\cline { 2 - 3 } & CON & MET & & 1.05 \\
\hline Body length $(\mathrm{cm})$ & 108.58 & 112.20 & 0.10 \\
Body weight $(\mathrm{kg})$ & 41.77 & 43.81 & 1.24 & 0.44 \\
Hip height $(\mathrm{cm})$ & 78.02 & 82.08 & 1.00 & 0.04 \\
Hip width $(\mathrm{cm})$ & 15.92 & 16.14 & 0.33 & 0.75 \\
Wither height $(\mathrm{cm})$ & 74.48 & 78.77 & 0.90 & 0.01 \\
\hline
\end{tabular}

Table 2 Blood plasma biomarkers at d 2 of age in Holstein calves ( $n=6 /$ group) born to cows randomly assigned to receive a basal control (CON) diet from $-28 \pm 2$ d to parturition [1.47 $\mathrm{Mcal} / \mathrm{kg}$ dry matter (DM) and $15.3 \%$ crude protein (CP)] with no added Met or CON plus ethyl cellulose Met (MET, Mepron ${ }^{\oplus}$, Evonik Nutrition \& Care GmbH, Germany)

\begin{tabular}{|c|c|c|c|c|}
\hline \multirow[t]{2}{*}{ Item } & \multicolumn{2}{|c|}{ Maternal diet } & \multirow[t]{2}{*}{ SEM } & \multirow{2}{*}{$\begin{array}{l}p \text { - } \\
\text { value }\end{array}$} \\
\hline & CON & MET & & \\
\hline Glucose (mmol/L) & 9.34 & 8.12 & 0.35 & 0.08 \\
\hline Cholesterol (mmol/L) & 0.96 & 0.89 & 0.07 & 0.64 \\
\hline Urea $(\mathrm{mmol} / \mathrm{L})$ & 3.32 & 3.56 & 0.24 & 0.62 \\
\hline $\mathrm{Ca}(\mu \mathrm{mol} / \mathrm{L})$ & 3.08 & 2.89 & 0.07 & 0.22 \\
\hline $\mathrm{P}(\mu \mathrm{mol} / \mathrm{L})$ & 2.39 & 2.27 & 0.05 & 0.29 \\
\hline $\mathrm{Mg}(\mu \mathrm{mol} / \mathrm{L})$ & 1.00 & 0.96 & 0.03 & 0.59 \\
\hline $\mathrm{Na}(\mu \mathrm{mol} / \mathrm{L})$ & 145.98 & 147.10 & 0.87 & 0.55 \\
\hline $\mathrm{K}(\mu \mathrm{mol} / \mathrm{L})$ & 4.82 & 5.44 & 0.19 & 0.12 \\
\hline $\mathrm{Cl}(\mu \mathrm{mol} / \mathrm{L})$ & 99.38 & 98.92 & 0.72 & 0.76 \\
\hline Zn $(\mu \mathrm{mol} / \mathrm{L})$ & 10.32 & 9.78 & 1.84 & 0.89 \\
\hline Ceruloplasmin $(\mu \mathrm{mol} / \mathrm{L})$ & 0.99 & 1.01 & 0.12 & 0.93 \\
\hline Albumin (g/L) & 26.64 & 27.86 & 0.47 & 0.21 \\
\hline AST (U/L) & 112.85 & 128.47 & 10.49 & 0.49 \\
\hline GGT (U/L) & $1,344.67$ & $1,406.67$ & 145.77 & 0.84 \\
\hline Bilirubin ( $\mu \mathrm{mol} / \mathrm{L})$ & 14.73 & 16.89 & 1.71 & 0.55 \\
\hline NEFA (mmol/L) & 0.28 & 0.34 & 0.05 & 0.60 \\
\hline Hydroxybutyrate $(\mathrm{mmol} / \mathrm{L})$ & 0.05 & 0.09 & 0.01 & 0.08 \\
\hline CREA $(\mu \mathrm{mol} / \mathrm{L})$ & 107.92 & 111.67 & 4.81 & 0.72 \\
\hline Paraoxonase (U/mL) & 12.27 & 13.02 & 1.15 & 0.76 \\
\hline $\mathrm{ROM}\left(\mathrm{mg} \mathrm{H} \mathrm{O}_{2} / 100 \mathrm{~mL}\right.$ ) & 13.14 & 12.86 & 0.75 & 0.87 \\
\hline $\operatorname{FRAP}(\mu \mathrm{mol} / \mathrm{L})$ & 164.50 & 171.50 & 8.31 & 0.70 \\
\hline $\mathrm{NO}_{x}(\mu \mathrm{mol} / \mathrm{L})$ & 194.00 & 239.33 & 22.31 & 0.33 \\
\hline $\mathrm{NO}_{2}^{-}(\mu \mathrm{mol} / \mathrm{L})$ & 16.87 & 10.33 & 2.56 & 0.26 \\
\hline $\mathrm{NO}_{3}{ }^{-}(\mu \mathrm{mol} / \mathrm{L})$ & 156.50 & 229.00 & 24.06 & 0.14 \\
\hline Insulin ( $\mu \mathrm{g} / \mathrm{L})$ & 1.05 & 0.70 & 0.16 & 0.29 \\
\hline
\end{tabular}

$($ Phe; $P$ value $=0.08)$ and Taurine $($ Tau; $P$ value $=0.06)$ in MET calves compared with CON (Table 3 ).

\section{Global DNA methylation and western blotting}

Maternal supplementation with Met led to greater ( $P$ value $<0.05)$ global DNA methylation compared with $\mathrm{CON}$ calves (Fig. 1). Among the proteins measured, the ratio of $p$-AKT:AKT (AKT Serine/Threonine Kinase) was greater in MET calves ( $P$ value $<0.001$; Table 4$)$. In contrast, MET calves had a lower ratio of p-S6K1:S6K1 $(P$ value $=0.01 ;$ Table 4$)$.

\section{Metabolomics, hepatic enzyme activity and mRNA abundance}

At day 4, maternal supplementation with MET led to greater concentrations ( $\mathrm{P}$ value $\leq 0.05$ ) of Glycine, 
Table 3 Plasma AA concentration at d 2 of age in Holstein calves ( $n=6 /$ group) born to cows randomly assigned to receive a basal control (CON) diet from $-28 \pm 2 \mathrm{~d}$ to parturition [1.47 $\mathrm{Mcal} / \mathrm{kg}$ dry matter (DM) and $15.3 \%$ crude protein (CP)] with no added Met or CON plus ethyl cellulose Met (MET, Mepron ${ }^{\oplus}$, Evonik Nutrition \& Care GmbH, Germany)

\begin{tabular}{|c|c|c|c|c|}
\hline \multirow{2}{*}{$\begin{array}{l}\text { Item } \\
(\mu \mathrm{M})\end{array}$} & \multicolumn{2}{|c|}{ Maternal diet } & \multirow[t]{2}{*}{ SEM } & \multirow{2}{*}{$\begin{array}{l}p \text { - } \\
\text { value }\end{array}$} \\
\hline & CON & MET & & \\
\hline Met & 0.55 & 0.74 & 0.15 & 0.53 \\
\hline Lys & 1.26 & 1.16 & 0.23 & 0.84 \\
\hline Thr & 1.67 & 1.52 & 0.22 & 0.77 \\
\hline Arg & 1.97 & 1.60 & 0.41 & 0.69 \\
\hline lle & 1.17 & 1.02 & 0.15 & 0.65 \\
\hline Leu & 1.99 & 1.94 & 0.18 & 0.90 \\
\hline Val & 2.89 & 3.39 & 0.30 & 0.41 \\
\hline His & 1.85 & 2.46 & 0.23 & 0.21 \\
\hline Phe & 0.46 & 0.66 & 0.06 & 0.08 \\
\hline Gly & 1.33 & 1.72 & 0.16 & 0.24 \\
\hline Ser & 0.80 & 1.03 & 0.11 & 0.29 \\
\hline Pro & 2.22 & 2.68 & 0.35 & 0.52 \\
\hline Ala & 2.77 & 2.26 & 0.36 & 0.55 \\
\hline Asp & 0.31 & 0.09 & 0.10 & 0.37 \\
\hline Glu & 1.36 & 1.19 & 0.24 & 0.77 \\
\hline Tau & 0.66 & 1.09 & 0.12 & 0.06 \\
\hline Asn & 0.59 & 0.72 & 0.11 & 0.58 \\
\hline Gln & 5.37 & 7.17 & 0.96 & 0.37 \\
\hline Citr & 0.95 & 1.08 & 0.13 & 0.63 \\
\hline Aabu & 0.08 & 0.10 & 0.01 & 0.56 \\
\hline Tyr & 0.97 & 1.30 & 0.18 & 0.39 \\
\hline Orn & 0.48 & 0.57 & 0.10 & 0.68 \\
\hline 1-Mhis & 0.47 & 0.59 & 0.05 & 0.30 \\
\hline 3-Mhis & 0.11 & 0.12 & 0.03 & 0.75 \\
\hline
\end{tabular}

Adenosine, Serine, Taurine, Cystathionine, Glutamate, Fumarate, NAD, NADH, Taurocholic acid, Glycocholic acid, Lithocholic acid, and Glycochenodeoxycholic acid (Table 5). In contrast, lower hepatic activity for cystathionine $\beta$-synthase (CBS) and 5methyltetrahydrofolate homocysteine methyltransferase (MTR) was detected in the MET calves (Table 6). Maternal supplementation with MET led to a lower abundance of Phosphate Cytidylyltransferase 1, Choline, Beta $(P C Y T 1 B ; P$ value $=0.04)$, an overall tendency toward lower abundance of Cysteine Dioxygenase Type 1 (CDO1) and greater abundance of Phosphatidylethanolamine $N$-Methyltransferase $(P E M T)$ and Methionine Adenosyltransferase $1 A$ $(M A T 1 A)$ respectively $(P$ value $\leq 0.10$; Table 7$)$.

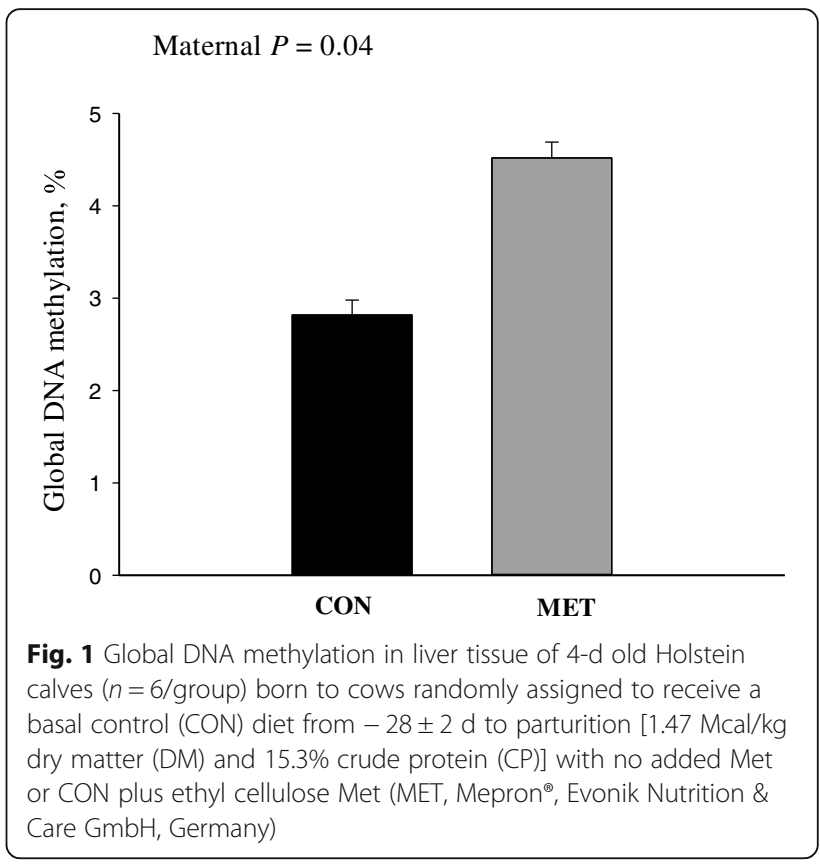

\section{RNA sequencing and gene expression analyses}

A summary of sequencing read alignment and mapping is reported in Additional File 1. Overall, samples had approximately 12 million reads of which 11 million ( 95\%) were uniquely mapped and 9.4 million $(\sim 78 \%)$ assigned to genes. Statistical analysis identified 13,867 uniquely annotated (EntrezID) genes. Of these, applying the 0.05 FDR cut-off, 74 genes (36 upregulated and 38 downregulated) were detected as differentially expressed (DEG) comparing MET with CON heifer calves, whereas 568 DEG (273 upregulated and 295 downregulated) were detected at FDR $\leq 0.10$ cut-off (Fig. 2). A summary of the top-ten up- and downregulated genes $(\mathrm{FDR} \leq 0.10)$ is reported in Tables 8 and 9. The entire list of DEG is reported in Additional File 2.

\section{KEGG pathway analysis}

The Dynamic Impact Approach (DIA) analysis yields the impact and flux of all the manually-curated pathways included in the KEGG database. The term 'impact' refers to the biological importance of a given pathway as a function of the change in expression of genes composing the pathway (proportion of DEG and their magnitude) in response to a treatment, condition, or change in physiological state. Consequently, the direction of the impact, or flux, characterizes the average change in expression as up-regulation/activation, down-regulation/ inhibition, or no change. Considering DIA results with DEG at $\mathrm{FDR} \leq 0.10$, a broad effect on the transcriptome due to maternal MET was detected (Fig. 3). All main KEGG categories, both metabolic ('Metabolism') and non-metabolic ('Environmental information processing', 
Table 4 Expression of mTOR pathway-related proteins in liver tissue from 4-d old Holstein calves ( $n=6 /$ group) born to cows randomly assigned to receive a basal control (CON) diet from $28 \pm 2 \mathrm{~d}$ to parturition [1.47 Mcal/kg dry matter (DM) and 15.3\% crude protein $(\mathrm{CP})]$ with no added Met or CON plus ethyl cellulose Met (MET, Mepron ${ }^{\oplus}$, Evonik Nutrition \& Care GmbH, Germany)

\begin{tabular}{lllll}
\hline $\begin{array}{l}\text { Protein (log- } \\
\text { transformed } \\
\text { data) }\end{array}$ & \multicolumn{2}{l}{ Maternal diet } & SEM & $\begin{array}{l}\boldsymbol{p} \text { - } \\
\text { value }\end{array}$ \\
\cline { 2 - 3 } $\begin{array}{llll}\text { Total protein } \\
\text { mTOR }\end{array}$ & MET & & \\
S6K1 & 0.93 & 0.90 & 0.08 & 0.85 \\
AKT & 2.55 & 2.38 & 0.10 & 0.43 \\
4EBP1 & 2.49 & 1.48 & 0.19 & $<.00$ \\
eEF2 & 2.39 & 2.42 & 0.17 & 0.93 \\
elF2a & 1.91 & 1.69 & 0.09 & 0.26 \\
RPS6 & 2.31 & 2.05 & 0.08 & 0.12 \\
Phosphorylated protein & & 2.33 & 0.21 & 0.57 \\
p-mTOR & 2.07 & & & \\
p-S6K1 & 0.62 & 0.69 & 0.06 & 0.59 \\
p-AKT & 2.61 & 1.62 & 0.18 & $<.00$ \\
p-4EBP1 & 2.46 & 2.24 & 0.11 & 0.36 \\
p-eEF2 & 1.50 & 1.58 & 0.10 & 0.72 \\
p-elF2a & 0.98 & 0.59 & 0.16 & 0.25 \\
p-RPS6 & 2.41 & 2.08 & 0.15 & 0.29 \\
Ratio & 1.78 & 1.17 & 0.21 & 0.15 \\
p-mTOR/mTOR & 0.74 & 0.85 & 0.12 & 0.69 \\
p-S6K1/S6K1 & 1.04 & 0.70 & 0.07 & 0.01 \\
p-AKT/AKT & 1.01 & 1.52 & 0.09 & $<.00$ \\
p-4EBP1/4EBP1 & 0.65 & 0.71 & 0.07 & 0.66 \\
p-eEF2/eEF2 & 0.51 & 0.36 & 0.08 & 0.35 \\
p-elF2a/elF2a & 1.04 & 1.01 & 0.05 & 0.73 \\
p-RPS6/RPS6 & 0.90 & 0.61 & 0.13 & 0.28 \\
\hline & & & & \\
\hline
\end{tabular}

'Cellular processes', and 'Organismal systems') were broadly impacted with a negative flux (i.e. downregulated), except for 'Genetic information processing' that was markedly upregulated (Fig. 3). In particular, 'Cell growth and death', 'Lipid Metabolism', 'Aging', 'Metabolism of Cofactors and Vitamins' and 'Signaling Molecules and Interaction' were the most-impacted and downregulated KEGG subcategories (Fig. 5). Along with 'Genetic Information Processing' pathways, the 'Nucleotide Metabolism', 'Glycan Biosynthesis and Metabolism', 'Environmental adaptation', 'Immune System' and 'Nervous system' were the most-impacted subcategories with a positive flux (i.e. upregulation) in MET vs. CON comparison (Fig. 3). Top-10 up- and downregulated single pathways are reported in Figs. 4 and 5, respectively.

\section{Transcription regulator discovery}

The transcription factor enrichment analysis with the ChIP-X Enrichment Analysis 3 (ChEA3) tool generated a list of 72 TF significantly-associated $(F D R \leq 0.05)$ with our DEG at the FDR $\leq 0.10$ threshold. The list of top 10ranked upstream regulators is reported in Table 10, whereas the entire list of TF is reported in Additional File 3. Applying the DIA approach to the ChEA3 results, the TF impact and flux values were predicted (Table 10).

\section{Discussion}

The present findings were broadly consistent with our previous reports investigating the effect of feeding MET during late-pregnancy on cow and calf hepatic function $[10,24,26,27,30,31,34,35]$. Briefly, in those previous studies enhanced MET supply improved immunometabolism along with DMI in dairy cows during the peripartal period and through peak lactation $[24,34,35]$. In the larger cohort of calves from this study encompassing birth through the first 9 wk. of life, we reported that maternal MET supply influenced enzyme activity and metabolome in one-carbon metabolism and the tricarboxylic acid (TCA) cycle, with beneficial physiological advantages to calves [26]. Furthermore, previous results on hepatic target-gene transcription have suggested that feeding Met during late-pregnancy was associated with faster maturation of key metabolic pathways involved in the calf's ability to quickly adapt to extrauterine life $[10,30]$. Thus, RNA-seq results alone revealed that feeding Met during late-gestation broadly altered neonatal calf liver transcriptome profiles. In particular, transcriptome profiles confirmed the hypothesis of an enhanced immunometabolic status attributable to the change in expression profiles of several genes mainly involved in 'Glucose metabolism', 'Lipid metabolism, 'Glutathione', and 'Immune System' metabolism.

Although the focus of the present integrative analyses only encompassed day 4 of age, together, the data supported the idea that feeding Met to enhance postruminal supply in the cow during late-gestation primed or programmed the Met cycle in calf liver, hence, contributing to better rates of growth and development [26]. For instance, the greater concentrations of adenosine and serine observed in MET calves at this early age support the hypothesis of a priming effect of the Met cycle. The conversion of Met to SAM is accompanied by ATP consumption in a reaction controlled by Met adenosyltransferase (MAT) [36] and after demethylation, SAM is converted to $\mathrm{SAH}$, which is subsequently hydrolyzed to homocysteine with the production of adenosine [37]. The tendency for greater MAT1A abundance in MET calves $(P$ value $<0.10$; Table 7$)$ supported this idea. In addition, the greater serine concentrations observed in 
Table 5 Metabolite concentrations ( $\mathrm{ng} / \mathrm{mg}$ of total protein) in liver tissue from 4-d old Holstein calves ( $n=6 / \mathrm{group}$ ) born to cows randomly assigned to receive a basal control (CON) diet from $-28 \pm 2 \mathrm{~d}$ to parturition [1.47 Mcal/kg dry matter (DM) and 15.3\% crude protein (CP)] with no added Met or CON plus ethyl cellulose Met (MET, Mepron ${ }^{\circledR}$, Evonik Nutrition \& Care GmbH, Germany)

\begin{tabular}{|c|c|c|c|c|}
\hline \multirow{2}{*}{$\begin{array}{l}\text { Metabolite, ( } \mathrm{ng} / \mathrm{mg} \text { of total } \\
\text { protein) }\end{array}$} & \multicolumn{2}{|c|}{ Maternal diet } & \multirow[t]{2}{*}{ SEM } & \multirow{2}{*}{$\begin{array}{l}p \text { - } \\
\text { value }\end{array}$} \\
\hline & CON & MET & & \\
\hline \multicolumn{5}{|l|}{ 1-Carbon metabolism } \\
\hline Adenosine & 3,855 & 8,411 & 1,052 & 0.02 \\
\hline Methionine & 979.29 & 1,566 & 254.08 & 0.29 \\
\hline Betaine & 15,282 & 21,058 & 3,424 & 0.44 \\
\hline Choline & 3,165 & 4,550 & 500.53 & 0.19 \\
\hline Glycine & 9,643 & 19,085 & 2,035 & 0.01 \\
\hline 5-Methyltetrahydrofolic acid & 8.06 & 12.08 & 2.67 & 0.49 \\
\hline N,N-Dimethylglycine & 33.67 & 55.76 & 7.74 & 0.18 \\
\hline S 5' Adenosyl homocysteine & 320.39 & 426.08 & 55.01 & 0.37 \\
\hline S 5' Adenosyl methionine & 773.97 & 630.38 & 74.81 & 0.36 \\
\hline Butyrobetaine & 69.95 & 112.76 & 14.61 & 0.17 \\
\hline \multicolumn{5}{|l|}{ Transsulfuration } \\
\hline Cystathionine & 346.41 & 738.41 & 95.37 & 0.04 \\
\hline Cysteine & 1,438 & 2,898 & 437.86 & 0.12 \\
\hline Cysteinesulfinic acid & 641.98 & 1,471 & 213.39 & 0.06 \\
\hline Glutamylcysteine & 909.72 & 1,041 & 144.79 & 0.67 \\
\hline Glutathione & 19,575 & 21,762 & 2,557 & 0.69 \\
\hline Hypotaurine & 2,929 & 5,879 & 1,080 & 0.20 \\
\hline Serine & 3,663 & 7,387 & 770.19 & 0.01 \\
\hline Taurine & 56,308 & 117,719 & 13,488 & 0.03 \\
\hline \multicolumn{5}{|l|}{ Tricarboxylic acid cycle } \\
\hline Ketoglutaric acid & 468.75 & 541.95 & 57.50 & 0.55 \\
\hline Fumarate & 1,775 & 3,504 & 419.50 & 0.04 \\
\hline Glutamate & 33,518 & 65,748 & 7,593 & 0.04 \\
\hline NAD & 10,074 & 23,436 & 2,829 & 0.01 \\
\hline FAD & 2,563 & 4,017 & 464.71 & 0.14 \\
\hline $\mathrm{NADH}$ & 3,796 & 7,733 & 994.65 & 0.05 \\
\hline Pyruvate & 1,656 & 1,974 & 293.37 & 0.62 \\
\hline Malic acid & 7,591 & 8,053 & 1,367 & 0.90 \\
\hline NAD/NADH & 2.75 & 3.68 & 0.47 & 0.35 \\
\hline \multicolumn{5}{|l|}{ Other } \\
\hline Glutamine & 2,567 & 5,256 & 1,216 & 0.36 \\
\hline Carnitine & 688.15 & 1170 & 160.62 & 0.16 \\
\hline \multicolumn{5}{|l|}{ Bile acids } \\
\hline Glycocholic acid & 6,444 & 10,845 & 1,054 & 0.05 \\
\hline Glycochenodeoxycholic acid & 2,627 & 5,438 & 666.36 & 0.04 \\
\hline Taurocholic acid & 1,829 & 3,106 & 271.17 & 0.02 \\
\hline Lithocholic acid & 7,796 & 26,284 & 3,501 & 0.01 \\
\hline Taurochenodeoxycholic acid & 1,738 & 3,010 & 320.82 & 0.06 \\
\hline
\end{tabular}


Table 6 Hepatic activity of betaine homocysteine methyltransferase (BHMT), cystathionine $\beta$-synthase (CBS), and 5methyltetrahydrofolate homocysteine methyltransferase (MTR) in liver tissue from 4 -d old Holstein calves ( $n=6 /$ group) born to cows randomly assigned to receive a basal control (CON) diet from $-28 \pm 2 \mathrm{~d}$ to parturition [1.47 Mcal/kg dry matter (DM) and $15.3 \%$ crude protein (CP)] with no added Met or CON plus ethyl cellulose Met (MET, Mepron ${ }^{\circledR}$, Evonik Nutrition \& Care $\mathrm{GmbH}$, Germany)

\begin{tabular}{lllll}
\hline $\begin{array}{l}\text { Enzyme } \\
\text { (nmol } \\
\text { product. } \\
\mathbf{h}^{-1} \cdot \mathbf{m g} \\
\text { protein }^{-1} \text { ) }\end{array}$ & Maternal diet & SEM & $\begin{array}{l}\boldsymbol{p} \text { - } \\
\text { value }\end{array}$ \\
\cline { 2 - 3 } CBS & CON & MET & & \\
MTR & 16.40 & 4.43 & 2.16 & $<.00$ \\
BHMT & 17.69 & 5.48 & 2.28 & 0.01 \\
\hline
\end{tabular}

MET calves supported this hypothesis, since it is known that serine supports the Met cycle by providing onecarbon units to regenerate Met from homocysteine and through de novo ATP synthesis [38]. In this context, the downregulation of Thymidylate synthase (TYMS) [FC= - 1.50] was also noteworthy. TYMS converts deoxyuridine monophosphate (dUMP) to deoxythymidine monophosphate (dTMP) in a 5,10-methylene-tetrahydrofolate (THF)-dependent reaction [39]. Its downregulation indirectly suggested a greater concentration of the most reduced form of folate $1 \mathrm{C}$ unit, 5-methyl-THF that has a unique cellular fate, the remethylation of homocysteine to form methionine [39]. In light of current and previous observations, we speculate that despite the lower activity of MTR in liver from MET calves, enzymatic efficiency might have been greater. More in-depth discussion on this point is available in Additional File 4.

The greater concentration of serine also indicated the potential for greater metabolic activity through the transsulfuration pathway in MET calves, an idea supported by the greater concentration of a number of metabolites including cystathionine and taurine. The former is the product of the CBS reaction using homocysteine and serine, which is considered rate-limiting in the transsulfuration pathway [9]. Thus, despite the lower CBS activity, based on the greater concentrations of a number of intermediate metabolites (e.g. cystathionine, cysteinesulfinic acid), we speculated that efficiency of the CBS reaction was such that flux through the transsulfuration pathway was overall greater in MET calves. As such, concentrations of the cellular antioxidant GSH [40] also increased, and could have elicited beneficial effects on antioxidant responses in the calves.

A greater degree of Met metabolism was also indirectly suggested in our experiment by the marked upregulation of the nucleotide metabolism pathway (Fig. 4), since the role played by Met in Purine synthesis is well-
Table 7 Abundance of genes related to methionine metabolism, DNA methylation, glutathione metabolism, and cytidine 5'-diphosphocholine (CDP)-choline pathway in liver tissue from 4- $d$ old Holstein calves ( $n=6 /$ group) born to cows randomly assigned to receive a basal control (CON) diet from $28 \pm 2 \mathrm{~d}$ to parturition [1.47 Mcal/kg dry matter (DM) and 15.3\% crude protein (CP)] with no added Met or CON plus ethyl cellulose Met (MET, Mepron ${ }^{\circledR}$, Evonik Nutrition \& Care GmbH, Germany)

\begin{tabular}{|c|c|c|c|c|}
\hline \multirow{2}{*}{$\begin{array}{l}\text { Gene } \\
\text { (log } \\
\text { scale) }\end{array}$} & \multicolumn{2}{|c|}{ Maternal diet } & \multirow[t]{2}{*}{ SEM } & \multirow{2}{*}{$\begin{array}{l}p \text { - } \\
\text { value }\end{array}$} \\
\hline & $\mathrm{CON}$ & MET & & \\
\hline \multicolumn{5}{|c|}{ Methionine cycle } \\
\hline MAT1A & 0.01 & 0.03 & 0.01 & 0.09 \\
\hline BHMT & 1.23 & 0.98 & 0.11 & 0.26 \\
\hline BHMT2 & 0.06 & 0.11 & 0.04 & 0.33 \\
\hline MTR & 0.73 & 1.04 & 0.11 & 0.19 \\
\hline SAHH & 0.04 & 0.10 & 0.01 & 0.53 \\
\hline PEMT & 0.09 & 0.17 & 0.02 & 0.07 \\
\hline$B A D H$ & 1.16 & 1.20 & 0.06 & 0.73 \\
\hline $\mathrm{CHDH}$ & 1.57 & 1.50 & 0.15 & 0.76 \\
\hline SARDH & 0.93 & 0.83 & 0.06 & 0.40 \\
\hline \multicolumn{5}{|c|}{ DNA methylation } \\
\hline DNMT1 & 0.95 & 0.94 & 0.03 & 0.93 \\
\hline DNMT3A & 0.97 & 0.88 & 0.05 & 0.36 \\
\hline \multicolumn{5}{|c|}{ Transsulfuration } \\
\hline CBS & 0.76 & 0.73 & 0.05 & 0.81 \\
\hline CDO1 & 0.91 & 0.74 & 0.05 & 0.08 \\
\hline CSAD & 0.34 & 0.30 & 0.02 & 0.37 \\
\hline $\mathrm{CTH}$ & 1.18 & 1.45 & 0.09 & 0.20 \\
\hline \multicolumn{5}{|c|}{ Glutathione pathway } \\
\hline GSS & 1.02 & 0.97 & 0.03 & 0.48 \\
\hline GCLC & 0.50 & 0.52 & 0.06 & 0.95 \\
\hline GSR & 0.61 & 0.70 & 0.04 & 0.27 \\
\hline GPX1 & 0.86 & 1.02 & 0.06 & 0.13 \\
\hline \multicolumn{5}{|c|}{ CDP-choline pathway } \\
\hline CHKA & 0.75 & 0.96 & 0.10 & 0.31 \\
\hline$C H K B$ & 0.76 & 0.76 & 0.03 & 0.94 \\
\hline PCYTIA & 0.94 & 0.98 & 0.05 & 0.66 \\
\hline PCYTIB & 0.82 & 0.50 & 0.08 & 0.04 \\
\hline CEPT1 & 0.94 & 0.96 & 0.05 & 0.92 \\
\hline
\end{tabular}

documented [41]. Considering that Met plays an essential role in epigenetics via DNA methylation [42] and that it has been demonstrated that maternal methyl donor supplementation during pregnancy can regulate epigenetics via DNA methylation [43], the overall upregulation of 'Genetic information processing' pathways was compatible with the greater global DNA methylation detected in MET calves (Fig. 1). The evident upregulation 


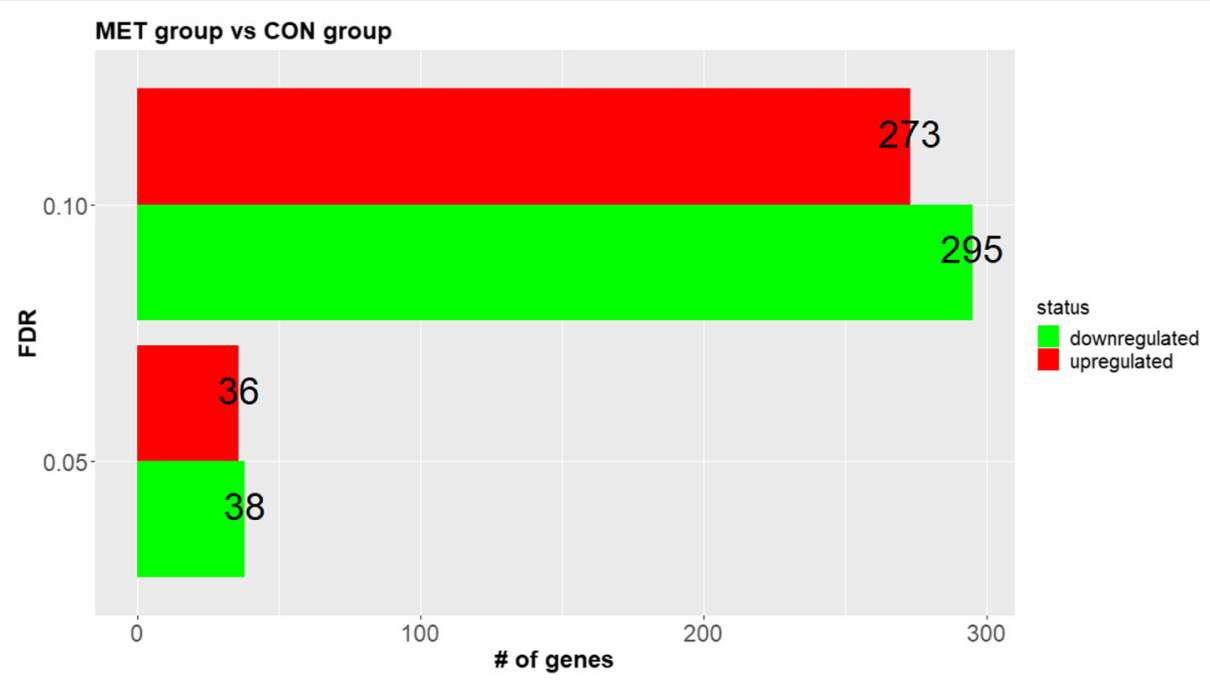

Fig. 2 Differentially expressed genes (DEG; at FDR $\leq 0.10$ and $\leq 0.05)$ from RNAseq data of liver tissue from 4-d old Holstein calves ( $n=6 / g r o u p)$ born to cows randomly assigned to receive a basal control (CON) diet from $-28 \pm 2 \mathrm{~d}$ to parturition $[1.47 \mathrm{Mcal} / \mathrm{kg}$ dry matter (DM) and $15.3 \%$ crude protein (CP)] with no added Met or CON plus ethyl cellulose Met (MET, Mepron ${ }^{\circledast}$, Evonik Nutrition \& Care GmbH, Germany). The green bars indicate downregulation, while the red bars indicate upregulation. The set of bars indicates differentially expressed genes at 0.05 and 0.10 FDR cut-offs considering in both cases the comparison of MET vs. CON

Table 8 Top 20 upregulated genes among those that were differentially expressed (DEG; FDR $\leq 0.10)$ in RNAseq data from liver tissue of 4 -d old Holstein calves ( $n=6 /$ group) born to cows randomly assigned to receive a basal control (CON) diet from $-28 \pm 2 \mathrm{~d}$ to parturition [1.47 Mcal/kg dry matter (DM) and $15.3 \%$ crude protein (CP)] with no added Met or CON plus ethyl cellulose Met (MET, Mepron ${ }^{\circledast}$, Evonik Nutrition \& Care GmbH, Germany)

\begin{tabular}{llll}
\hline Entrez gene id & Gene Symbol & FC & FDR \\
\hline 618,238 & M-SAA3.2 & 5.70 & 0.08 \\
520,625 & SLC44A4 & 4.46 & 0.07 \\
516,626 & SLC51A & 4.06 & 0.09 \\
516,291 & REC8 & 3.88 & 0.07 \\
782,922 & LOC782922 & 3.72 & 0.10 \\
281,644 & BFSP1 & 3.42 & 0.04 \\
530,071 & CRIP3 & 2.97 & 0.09 \\
505,642 & GSTO1 & 2.85 & 0.08 \\
514,770 & NROB2 & 2.64 & 0.05 \\
527,458 & KLHL26 & 2.58 & 0.08 \\
504,950 & NPM3 & 2.58 & 0.05 \\
523,874 & FAM184B & 2.38 & 0.10 \\
613,523 & EAF2 & 2.32 & 0.08 \\
514,979 & CLEC6A & 2.30 & 0.08 \\
506,900 & HIST1H2AC & 2.27 & 0.10 \\
536,607 & ACTN2 & 2.21 & 0.09 \\
$104,968,464$ & RPP21 & 2.09 & 0.04 \\
509,463 & ATCAY & 2.07 & 0.09 \\
506,043 & FKBP11 & 2.04 & 0.09 \\
$100,848,337$ & BHLHA15 & 2.02 & 0.07 \\
\hline & & &
\end{tabular}

Table 9 Top 20 downregulated genes among those that were differentially expressed (DEG; FDR $\leq 0.10)$ in RNAseq data from liver tissue of 4 -d old Holstein calves ( $n=6 /$ group) born to cows randomly assigned to receive a basal control (CON) diet from $-28 \pm 2 \mathrm{~d}$ to parturition [1.47 Mcal/kg dry matter (DM) and $15.3 \%$ crude protein (CP)] with no added Met or CON plus ethyl cellulose Met (MET, Mepron ${ }^{\circledR}$, Evonik Nutrition \& Care GmbH, Germany)

\begin{tabular}{llll}
\hline Entrez gene id & Gene Symbol & FC & FDR \\
\hline 527,436 & MSI1 & -4.89 & 0.07 \\
538,404 & MYOM1 & -4.08 & 0.07 \\
521,822 & FADS2 & -4.02 & 0.08 \\
526,134 & SLC9A2 & -3.90 & 0.09 \\
533,161 & KIF2C & -3.78 & 0.08 \\
518,623 & LOC518623 & -3.60 & 0.08 \\
327,679 & CCNB1 & -3.59 & 0.07 \\
518,801 & CFAP43 & -3.40 & 0.05 \\
528,813 & SCNN1D & -3.23 & 0.08 \\
537,698 & GRIK5 & -3.22 & 0.06 \\
281,061 & CDK1 & -3.15 & 0.08 \\
281,883 & KCNJ2 & -3.12 & 0.07 \\
534,781 & PBK & -3.06 & 0.09 \\
504,746 & ECT2 & -2.82 & 0.09 \\
616,767 & PRRG4 & -2.81 & 0.10 \\
518,313 & KIAA1324L & -2.77 & 0.08 \\
538,436 & CCNE2 & -2.72 & 0.04 \\
785,540 & LOC785540 & -2.65 & 0.09 \\
517,383 & GPRIN1 & -2.42 & 0.08 \\
615,890 & SMG8 & -2.40 & 0.08 \\
\hline & & &
\end{tabular}




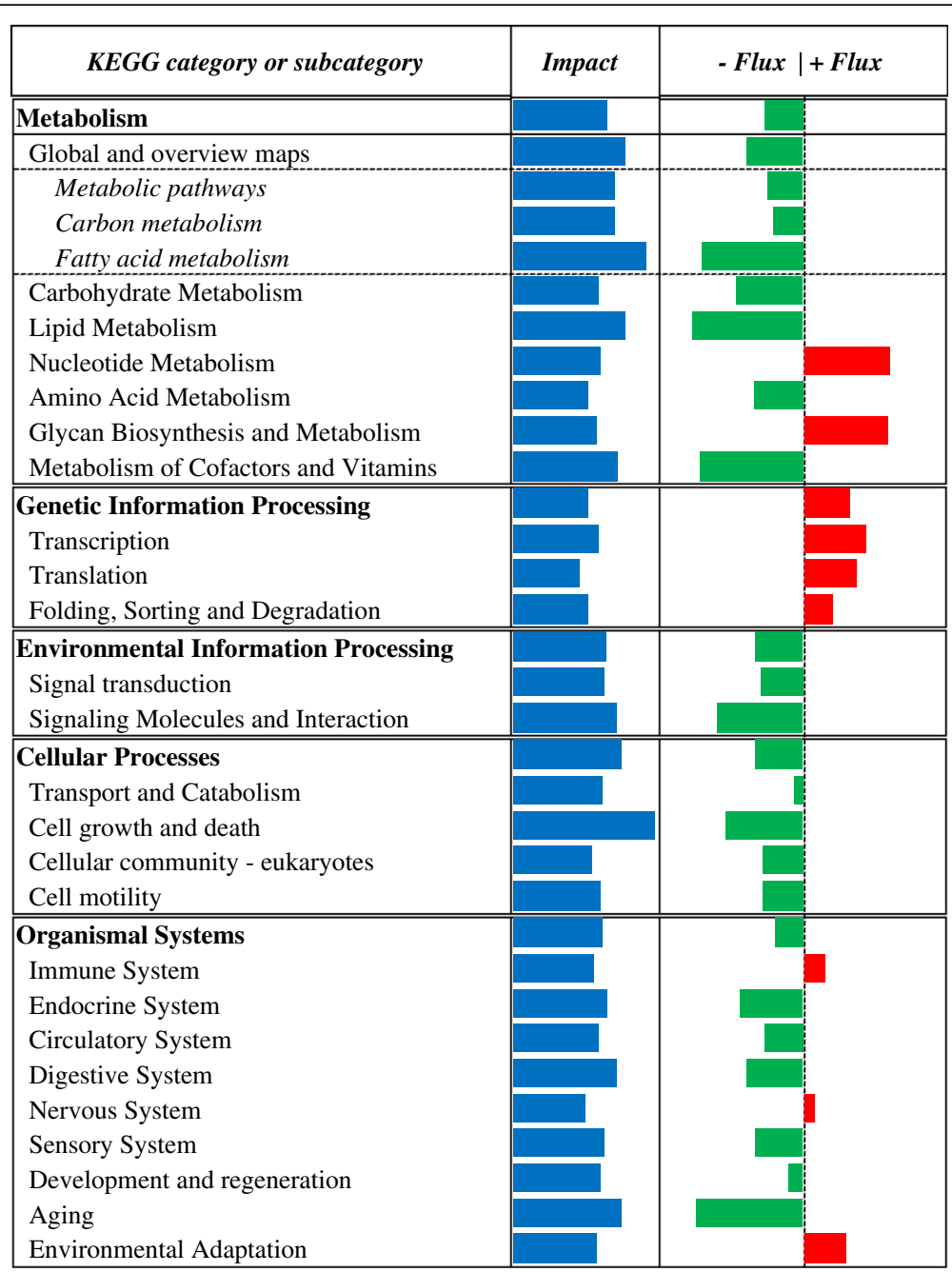

Fig. 3 Summary of KEGG metabolic subcategories resulting from the DIA analysis of liver tissue transcriptome from 4-d old Holstein calves ( $n=6 /$ group) born to cows randomly assigned to receive a basal control (CON) diet from $-28 \pm 2 \mathrm{~d}$ to parturition [1.47 Mcal/kg dry matter (DM) and 15.3\% crude protein (CP)] with no added Met or CON plus ethyl cellulose Met (MET, Mepron`, Evonik Nutrition \& Care GmbH, Germany). The columns represent the effect (impact) and flux responses. The blue bars represent the effect value (0 to 300$)$, and the flux columns represent negative (-) and positive (+) flux ( -300 to +300$)$ based on the direction of the effect. The positive flux (red bars) indicates an upregulation in treated (MET) liver tissue cells compared to control (CON) ones, while the negative flux (green bars) indicates a downregulation

of TRMT61A (tRNA Methyltransferase 61A) [FC = 1.69] was consistent with this scenario, as well as the upregulation of POLR3H (RNA Polymerase III Subunit H) [FC = 1.72] and POLR2I (RNA Polymerase II Subunit I) $[\mathrm{FC}=$ 1.71] (Additional File 2). In this context, the marked upregulation of histone $H I S T 1 H 2 A C$ [FC $=2.27$ ] was noteworthy considering that SAM is also the most-important methyl-donor for histone methyltransferases [44]. Recent studies demonstrated how increased SAM and histone methylation levels are associated with genetic ablation of MAT in Saccharomyces pombe [45]. In the general context of nutritional programming, the marked upregulation of Meiotic recombination REC8 [FC $=3.88$ ] and downregulation of cyclin B1 (CCNB1) [FC = -3.59] and cyclin-dependent kinase 1 (CDK1) [FC $=-3.15]$ was intriguing. These changes could potentially be biologically-relevant considering the role of these genes in oocyte meiosis $[46,47]$ and that methionine adenosyltransferase 2B (MAT2B) influences oocyte maturation in mouse by regulating the MAPK pathway [48]. Further studies will have to be performed to ascertain the mechanistic relevance of these changes in the context of hepatic nutritional programming of the calf.

\section{Glucose metabolism}

Studies in humans and mice suggest that DNA methylation plays a crucial role in tissue-specific insulin-induced gene expression [49]. Both in vivo and in vitro studies confirmed that AKT is an indicator of hepatic and adipose insulin sensitivity in dairy cows $[50,51]$. Thus, the 


\begin{tabular}{|l|l|l|l|l|}
\hline \multicolumn{1}{|c|}{ Category } & \multicolumn{1}{|c|}{ Subcategory } & \multicolumn{1}{c|}{ KEGG Pathway } & Impact & - Flux ++ Flux \\
\hline 1. Metabolism & 1.4 Nucleotide Metabolism & Purine metabolism & \\
1. Metabolism & 1.7 Glycan Biosynthesis and Metabolism & N-Glycan biosynthesis & \\
1. Metabolism & 1.7 Glycan Biosynthesis and Metabolism & Various types of N-glycan biosynthesis & \\
2. Genetic Information Processing & 2.1 Transcription & RNA polymerase & \\
2. Genetic Information Processing & 2.2 Translation & RNA transport & \\
2. Genetic Information Processing & Ribosome & \\
2. Genetic Information Processing & 2.3 Folding, Sorting and Degradation & Proteasome & \\
4. Cellular Processes & Phagosome & \\
5. Organismal Systems & C.1 Transport and Catabolism & C-type lectin receptor signaling pathway & \\
5. Organismal Systems & 5.1 Immune System & & \\
\hline
\end{tabular}

Fig. 4 Summary of top-10 upregulated KEGG pathways resulting from the DIA analysis of liver tissue transcriptome from 4-d old Holstein calves ( $n=6 /$ group) born to cows randomly assigned to receive a basal control (CON) diet from $-28 \pm 2 \mathrm{~d}$ to parturition [1.47 Mcal/kg dry matter (DM) and $15.3 \%$ crude protein (CP)] with no added Met or CON plus ethyl cellulose Met (MET, Mepron ${ }^{\oplus}$, Evonik Nutrition \& Care GmbH, Germany). The columns represent the effect (impact) and flux responses. The blue bars represent the effect value ( 0 to 300 ), and the flux columns represent negative $(-)$ and positive (+) flux $(-300$ to +300$)$ based on the direction of the effect. The positive flux (red bars) indicates an upregulation in treated (MET) liver tissue cells compared to control (CON) ones, while the negative flux (green bars) indicates a downregulation

greater phosphorylated AKT ratio in MET calves suggested they were more sensitive to insulin, which is consistent with the tendency for lower plasma glucose concentrations in those calves $(P$ value $=0.08$; Table 2$)$ despite the lack of statistical difference in insulin concentrations. In this regard, it is also noteworthy that (at least in non-ruminants) AKT phosphorylates and stimulates sterol regulatory element binding transcription factor 1c (SREPB1c) leading to enhanced liver lipogenesis through the suppression of insulin induced protein 2 (INSIG2). INSIG2 is a protein of the endoplasmic reticulum that blocks the activation of SREBP1c by binding to SREBP cleavage-activating protein (SCAP) and prevents it from escorting SREBPs to the Golgi [52]. This scenario was confirmed in our experiment by the significant downregulation of INSIG2 [FC $=-1.35$ ], and the fact that at this age of the calf most of the supply of fatty acids (FA) are derived from consuming milk replacer.
The lower phosphorylated S6K1 (Ribosomal Protein S6 Kinase) ratio in MET calves was intriguing considering that S6K1 is the predominant regulatory kinase of GSK3 (Glycogen synthase kinase 3) [53] and that AKT is known to inactivate GSK3 $\beta$ [54], one of the two isoforms of GSK3. In this context, the significant downregulation of PCK1 (Phosphoenolpyruvate Carboxykinase 1) [FC= -1.99] is in line with the fact that most of the circulating glucose in newborn calves arises from lactose in the milk replacer fed. The downregulation of FOXO4 (Forkhead Box O4) [FC $=-1.44$ ] also agreed with this idea, since the FOXO complex binds the PCK1 promoter [55].

It is well-established that lactose intake on its own is not sufficient to meet the newborn glucose demands [56], thus, calves have to establish endogenous glucose production and gluconeogenesis [57]. In this regard, hepatic glycogen stored during late-gestation represents an important energy source that is quickly exhausted

\begin{tabular}{|c|c|c|c|c|}
\hline Category & Subcategory & KEGG Pathway & Impact & -Flux $\mid+$ Flux \\
\hline 1. Metabolism & 1.1 Carbohydrate Metabolism & Inositol phosphate metabolism & & \\
\hline 1. Metabolism & 1.3 Lipid Metabolism & Biosynthesis of unsaturated fatty acids & & \\
\hline 1. Metabolism & 1.3 Lipid Metabolism & Steroid hormone biosynthesis & & \\
\hline 1. Metabolism & 1.8 Metabolism of Cofactors and Vitamins & Retinol metabolism & & \\
\hline 3. Environmental Information Processing & 3.3 Signaling Molecules and Interaction & Neuroactive ligand-receptor interaction & & \\
\hline 4. Cellular Processes & 4.2 Cell growth and death & p53 signaling pathway & & \\
\hline 4. Cellular Processes & 4.2 Cell growth and death & Cell cycle & & \\
\hline 5. Organismal Systems & 5.2 Endocrine System & PPAR signaling pathway & & \\
\hline 5. Organismal Systems & 5.2 Endocrine System & Thyroid hormone signaling pathway & & \\
\hline 5. Organismal Systems & 5.9 Aging & Longevity regulating pathway - multiple species & & \\
\hline
\end{tabular}

Fig. 5 Summary of top-10 downregulated KEGG pathways resulting from the DIA analysis of liver tissue transcriptome from 4-d old Holstein calves ( $n=6 /$ group) born to cows randomly assigned to receive a basal control (CON) diet from $-28 \pm 2 \mathrm{~d}$ to parturition [1.47 Mcal/kg dry matter (DM) and $15.3 \%$ crude protein (CP)] with no added Met or CON plus ethyl cellulose Met (MET, Mepron ${ }^{\oplus}$, Evonik Nutrition \& Care GmbH, Germany). The columns represent the effect (impact) and flux responses. The blue bars represent the effect value (0 to 300), and the flux columns represent negative $(-)$ and positive (+) flux $(-300$ to +300$)$ based on the direction of the effect. The positive flux (red bars) indicates an upregulation in treated (MET) liver tissue cells compared to control (CON) ones, while the negative flux (green bars) indicates a downregulation 
Table 10 Summary of the top 10-ranked upstream regulators (TF) out of the 72 identified using the ChEA3 tool and significantly associated (FDR cutoff $\leq 0.05$ ) with our differentially expressed gene (DEG) list obtained in RNAseq data from liver tissue of 4-d old Holstein calves ( $n=6 /$ group) born to cows randomly assigned to receive a basal control (CON) diet from $-28 \pm 2 \mathrm{~d}$ to parturition [1.47 Mcal/kg dry matter (DM) and 15.3\% crude protein (CP)] with no added Met or CON plus ethyl cellulose Met (MET, Mepron ${ }^{\circledR}$, Evonik Nutrition \& Care GmbH, Germany)

\begin{tabular}{|c|c|c|c|c|c|c|c|}
\hline TF & Impact & Flux & $\begin{array}{l}\text { Predicted } \\
\text { State }\end{array}$ & Rank & $\begin{array}{l}P \\
\text { value }\end{array}$ & FDR & Overlapping DEG \\
\hline MYC & 178.42 & 57.40 & Activated & 1 & $\begin{array}{l}4.11 \mathrm{E}- \\
09\end{array}$ & $\begin{array}{l}1.26 \mathrm{E}- \\
06\end{array}$ & $\begin{array}{l}\text { POP1, GMFG, SMC4, KRTCAP2, CDK5RAP3, IER2, CLPP, DDIT3, UBA52, RPL28, NPRL2, ABCB8, } \\
\text { ANAPC11, BLOC1S6, PRKAR2A, TOE1, NR1D2, NFATC4, MRPL38, ABCC10, CYB561D2, MCEE, } \\
\text { GSTO1, SUMF1, RNF167, TUT1, SF3B5, RIDA, PSMB2, BID, SF3A2, TARBP2, LAMTOR2, HSPA1A, } \\
\text { STK16, MAP 2 K3, CNPY3, LENG1, SNRPA, ENY2, INO80E, GOT1, DHCR24, FOXN2, G6PC3, } \\
\text { TMEM11, RAD9A, BMPR2, ZC3H3, MRPL4, NGRN, GPX1, REXO4, EVC, SNRPA1, ZBTB44, } \\
\text { MRM1, NCLN, POLR21, POLR2I, ATOX1, KLF5, KLF9, POLR3H, EIF4A2, SMARCB1, NUBP1, } \\
\text { NUBP2, SNRPD1, RPL36AL, PDK1, ALG5, MRPS18B, MRPS18A, ALG3, IMP4, SNX4, PTDSS2, } \\
\text { VAT1, ALDH6A1, CALM3, SUGP1, FKBP11, SLC44A4, GRIK5, GUK1, SEC61B, PRMT6, TMED9, } \\
\text { NME1, APRT, RPUSD4, KIF2C, YAP1, NEDD8, NT5C, PES1, NPM3, GEMIN2, NR3C1, CHCHD1, } \\
\text { ZGPAT, DPM2, DOK2, CCNE2, CCNB1, SHARPIN, DHRS7B, RHBDD3, NONO, DLG1, NABP2, } \\
\text { COPE, CHD9, DDX41, YWHAG, PEX1, EEF1D, DOCK1, PFDN6, PNKP, PSMB10, TBRG4, PRRG4, } \\
\text { RMND5A, MAPK6, SLC5OA1, WEE1 }\end{array}$ \\
\hline
\end{tabular}

E2F1 $178.13 \quad 31.67$ Activated $2 \quad$ 7.28E- 7.45E- SMC4, SMC2, MYC, MPV17, CDK5RAP3, IER2, VPS18, AARSD1, RNF125, CLPP, DDIT3, RPL28, 0806 RPN1, ABCB8, ANAPC11, BLOC156, MCTS1, TOE1, MCAT, VANGL1, ADI1, MMS19, MRPL38, ING1, NUDC, ANXA4, SUMF1, CDC42EP5, TUT1, SF3B5, AHNAK, RNF138, BID, SF3A2, TARBP2, DCBLD2, SNX15, ATCAY, STK16, CNPY2, LENG1, UTRN, ENY2, FECH, FOXO4, ATXN7, AMDH D2, EIF2B4, GOT1, DHCR24, FOXN2, TMEM11, RAD9A, MRPL4, NGRN, GPX1, REXO4, COASY, SNRPA1, TSSC4, GTF3C5, HM13, MRM1, SH3BP2, POLR2G, FNIP1, KCNJ2, FOXJ3, GFER, ATOX1, KLF5, KLF9, SLC25A30, POLR3H, EIF4A2, SMARCB1, NUBP1, NUBP2, SNRPD1, RPL36AL, EIF2D, TNS3, PDK1, CPT1A, ACTN2, MRPS18B, MRPS18A, ALG3, IMP4, PLPP3, PTDS S2, RACGAP1, VAT1, EAF2, FKBP11, INTS11, MRPS11, CITED4, ROBO1, ACADM, PRMT6, ZFX, ZDHHC17, NME1, APRT, KIF2C, YAP1, UQCR11, TYMS, NT5C, PES1, SCAND1, YIPF1, ITCH, GEMIN2, CHCHD1, HIST1H2AC, ZGPAT, ACYP2, ALDH3A2, DPM2, CCNE2, RPP21, COX19, DPP4, SHARPIN, DHRSTB, ECT2, KLHL26, NONO, HSPA2, TJAP1, BRWD1, PICALM, DDX41, ADGRE5, ARHGEF10, TSFM, PEX1, ETV5, TRAPPC6A, EEF1D, CAT, PFDN6, PNKP, PPP2R3C, TAF10, WEE1, CDK2AP2

CREB1 174.6124 .88 Activated 3 2.87E- 2.20E- KRTCAP2, IER2, CHID1, VPS18, BIN3, BIN1, DDIT3, FDX2, PRKD2, UBA52, EXD2, CDCA2, ANAP $07 \quad 05$ C11, BLOC1S6, MCTS1, IRF2BP2, TYSND1, NR1D2, FOSL2, MMS19, ING1, CYB561D2, EMD, TUT1, PPARA, SF3B5, PSMB2, TARBP2, SNX15, LAMTOR2, CHPF, LTN1, GOLIM4, FADS2, STK16, MAP 2 K3, CNPY3, SNRPA, ENY2, RLF, EIF2B4, GOT1, TMEM11, CPD, ZC3H3, MRPL4, DAD1, TSSC4, HM13, CXXC1, NCLN, SEC11C, SPAG9, OXR1, KLF6, KLF5, KLF9, TRMT61A, EIF4A2, PANK3, JMJD1C, TXNDC16, NUBP2, EFR3A, GOLPH3L, PREB, APOB, ZRANB1, EAF2, NDUFAF3, CALM3, SUGP1, GUK1, TMED9, KIF2C, AMIGO1, RTL6, CHCHDI, ALG12, BRMS1, SHARPIN, ANKZF1, CBX8, RHBDD3, DENND4A, NONO, NABP2, GMPPA, YWHAG, YWHAZ, ETV5, EEF1D, HLF, NR2C2, PSMB10, MAPK6, TAF10, WEE1, CDK2AP2, RBM42

PPARG $178.93-68.11$ Inhibited 4

$\begin{array}{ll}5.64 \mathrm{E}- & 3.46 \mathrm{E}- \\ 07 & 05\end{array}$
9.92E- 4.19E- SPI1, KRTCAP2, MYC, AARSD1, CLPP, RPN1, TYSND1, VANGL1, ADI1, MRPL38, EMD, GSTO1, 0705 TUT1, SNX15, SMCHD1, SNRPA, FECH, CORO1A, EIF2B4, GOT1, DHCR24, COPS9, SORD, SNRP A1, HM13, CXXC1, NCLN, SEC11C, NUBP2, SNRPD1, SOX6, PDK1, ECH1, IMP4, PREB, SYMPK, CALM3, IDE, RAC2, TMED9, UQCR11, NEDD8, NT5C, CHCHD1, HIST1H2AC, CYBA, BRMS1, RPP21, PPIH, RPS19BP1, ACBD5, NABP2, GCLM, PPP1R9B, YWHAG, TRAPPC6A, CAT, PFDN6, TBRG4, TAFIO

SPI1 $\quad 173.45 \quad 5.80 \quad$ Activated $5 \quad 9.49 \mathrm{E}-4.19 \mathrm{E}-$

SPI1, GMFG, SLC4A4, SCP2, PSMD4, NAMPT, CDK5RAP3, IER2, RNF125, PRKD2, RPL28, EXD2,
ZC3H12D, SCP2, MYC, NAMPT, WDR91, IER2, CHID1, AARSD1, HDHD5, RNF125, BIN3, CLPP, DDIT3, PRKD2, RPL28, RPN1, MRPL16, PRKAR2A, IRF2BP2, RMDN2, FOSL2, FERMT1, PAH, MTMR10, EEA1, GSTO1, ANXA5, SUMF1, KAT2B, HEATR5A, AEBP2, TUT1, PLCB1, AHNAK, BID, RNLS, BBOX1, TARBP2, LAMTOR5, UHRF1BP1L, MYLK4, FADS2, CDH2, ZBTB39, UTRN, ENY2, AMDHD2, GOT1, FOXN2, CDK1, MDM2, SERINC5, NGRN, GPX1, PIK3CA, MET, GTF3C5, ROCK2, GLRX, MRM1, FNIP1, POLR2J, CYB5A, FOXJ3, DDHD2, PTPN12, CDC42BPA, KBTBD11, BICC1, KLF6, NAGK, KLF9, SLC25A30, PANK3, SMARCB1, TNS3, CPT1A, ECH1, MRPS18B, MRPS18A, PREB, PLPP3, CFTR, STK38L, PCK1, ZRANB1, MYO5C, CUTC, IDE, ROBO1, ACADM, ZDHHC17, RPUSD4, CD47, C1QB, SH3BGRL, KLB, GEMIN2, SSC4D, SELENOP, COX19, COBLL1, ACBD5, CRIM1, HOOK3, ARHGAP25, TJAP1, DLG1, GCLM, PICALM, CHD9, TNFAIP3, PPPIR9B, ADGRE5, YWHAG, ARHGEF10, PEX1, YWHAZ, ACOX1, CAT, KDM7A, USP12, NR2C2, PSMB10, RMNDSA, TNKS2, MAPK6, TMEM3OB, CMTM4 CFP, BLOC156, WDR70, MCTS1, NR1D2, NFATC4, FERMT1, PYGL, ING1, PQBP1, EEA1, TRMT112, MRPL42, GSTO1, ANXA4, GMIP, SUMF1, RNF167, TUT1, PPARA, FAM214A, APOLD1, BID, PET100, LAPTM5, PSMB8, LAMTOR2, GOLIM4, MYLK4, PYCARD, ATCAY, STK16, MAP 2 K3, TPM1, CNPY3, CLIP1, CORO1A, YBEY, AMDHD2, MAP 3 K20, GOT1, CYBRD1, DHCR24, FOXN2, BFSP1, G6PC3, CPD, CCDC22, SERINC5, NGRN, PSTPIP1, SORD, DAD1, ROCK2, UNC93B1, CXXC1, GLRX, HSD17B11, HECTD1, SH3BP2, POLR2G, PTPN18, PTPN12, OXR1, FBXL12, 
Table 10 Summary of the top 10-ranked upstream regulators (TF) out of the 72 identified using the ChEA3 tool and significantly associated (FDR cutoff $\leq 0.05$ ) with our differentially expressed gene (DEG) list obtained in RNAseq data from liver tissue of 4-d old Holstein calves ( $n=6 /$ group) born to cows randomly assigned to receive a basal control (CON) diet from $-28 \pm 2 \mathrm{~d}$ to parturition [1.47 Mcal/kg dry matter (DM) and 15.3\% crude protein (CP)] with no added Met or CON plus ethyl cellulose Met (MET, Mepron ${ }^{\oplus}$, Evonik Nutrition \& Care GmbH, Germany) (Continued)

\begin{tabular}{|c|c|c|c|c|c|c|c|}
\hline $\mathrm{TF}$ & Impact & Flux & $\begin{array}{l}\text { Predicted } \\
\text { State }\end{array}$ & Rank & $\begin{array}{l}P \\
\text { value }\end{array}$ & FDR & Overlapping DEG \\
\hline & & & & & & & $\begin{array}{l}\text { SLC25A30, PANK3, JMJD1C, MRPS18B, MAP 7, STK38L, ASL, CD 14, STK11IP, STAG2, } \\
\text { NDUFAF3, RAC2, TMED9, ZFX, ZDHHC17, VAV1, C1QB, TOR4A, AIF1, PES1, C1QC, WASHC4, } \\
\text { NR3C1, EME2, KNTC1, ZGPAT, ACYP2, CYBA, TYROBP, RPS19BP1, CCNB1, CBX8, ACBD5, } \\
\text { HOOK3, ARHGAP25, BRWD1, PICALM, CHD9, PPP1R9B, GMPPA, CNPPD1, YWHAZ, ETV5, CAT, } \\
\text { PNKP, USP12, TBRG4, STOM, TAF10, SLC5OA1, BUD13 }\end{array}$ \\
\hline ZFX & 170.08 & 15.72 & Activated & 7 & $\begin{array}{l}1.23 \mathrm{E}- \\
06\end{array}$ & $\begin{array}{l}4.19 \mathrm{E}- \\
05\end{array}$ & $\begin{array}{l}\text { NCKAP1, PSMD4, NAMPT, IER2, AARSD1, HDHD5, CLPP, UBA52, RPL28, RPN1, ABCB8, ANAP } \\
\text { C11, PRKAR2A, TTPA, TOE1, MCAT, NROB2, VANGL1, ADI1, MRPL38, EEA1, EMD, NUDC, } \\
\text { GSTO1, SUMF1, AHNAK, PSMB2, RNF138, SC5D, BID, SF3A2, TARBP2, DCBLD2, STK16, } \\
\text { ZBTB39, CNPY2, CNPY3, LENG1, CLIP1, FKBP9, SNRPA, ENY2, FECH, ATXN7, NEK9, FOXN2, } \\
\text { BFSP1, G6PC3, MDM2, RAD9A, ISY1, MRPL4, REXO4, COASY, EVC, SNRPA1, GTF3C5, ZBTB44, } \\
\text { FNIP1, FOXJ3, ATOX1, SLC25A30, POLR3H, EIF4A2, PANK3, SMARCB1, SNRPD1, FBXO3, TNS3, } \\
\text { PDK1, MRPSI8A, NEIL2, FNDC4, SNX4, PTDSS2, STK38L, RAC2, PRMT6, ZFX, ZDHHC17, VAV1, } \\
\text { AMIGO1, PES1, SCAND1, ITCH, GEMIN2, RTL6, ZGPAT, CYBA, ALDH3A2, DPM2, CCNE2, } \\
\text { RHBDD3, KLHL26, NONO, TJAP1, NABP2, GCLM, BRWD1, CHD9, ADGRE5, ETV5, TRAPPC6A, } \\
\text { LATS2, ACOX1, EEF1D, ZMYND11, CLN5, TBRG4, MARVELD2, MAPK6, TMEM3OB, CMTM4, } \\
\text { WEE1, CDK2AP2, BUD13 }\end{array}$ \\
\hline CEBPB & 167.51 & 36.64 & Activated & 8 & $\begin{array}{l}1.79 \mathrm{E}- \\
06\end{array}$ & $\begin{array}{l}5.00 \mathrm{E}- \\
05\end{array}$ & $\begin{array}{l}\text { MYC, CHID1, AARSD1, BIN3, RUFY3, FDX2, CFP, NR2C2AP, TOE1, TYSND1, RMDN2, MCAT, } \\
\text { ABCC10, CYB561D2, EMD, PCMTD1, GMIP, RNF167, PLCB1, PDF, PSMB8, LAMTOR5, CHPF, } \\
\text { MPV17L2, STK16, ZBTB39, CNPY2, INSIG2, FBXO48, FOXO4, RLF, IP6K2, BCL3, RAD9A, COPS9, } \\
\text { NGRN, CXXC1, MRM1, POLR2G, FOXI3, PTPN12, OXR1, GFER, KBTBD11, FBXL12, KLF6, } \\
\text { SLC25A30, NUBP2, RPL36AL, ECH1, IMP4, PREB, SNX4, STK38L, B4GALNT1, ZRANB1, FKBP11, } \\
\text { IDE, GUK1, STBD1, SEC61B, PRMT6, TMED9, CYBA, CBX8, RHBDD3, PICALM, ARHGEF10, } \\
\text { TSFM, EEF1D, NR2C2, MAPK6, LUM, TAF10, SLC5OA1, MAPK12, CDK2AP2, BUD13 }\end{array}$ \\
\hline HNF4A & 175.29 & -51.68 & Inhibited & 9 & $\begin{array}{l}3.65 \mathrm{E}- \\
06\end{array}$ & $\begin{array}{l}9.34 \mathrm{E}- \\
05\end{array}$ & 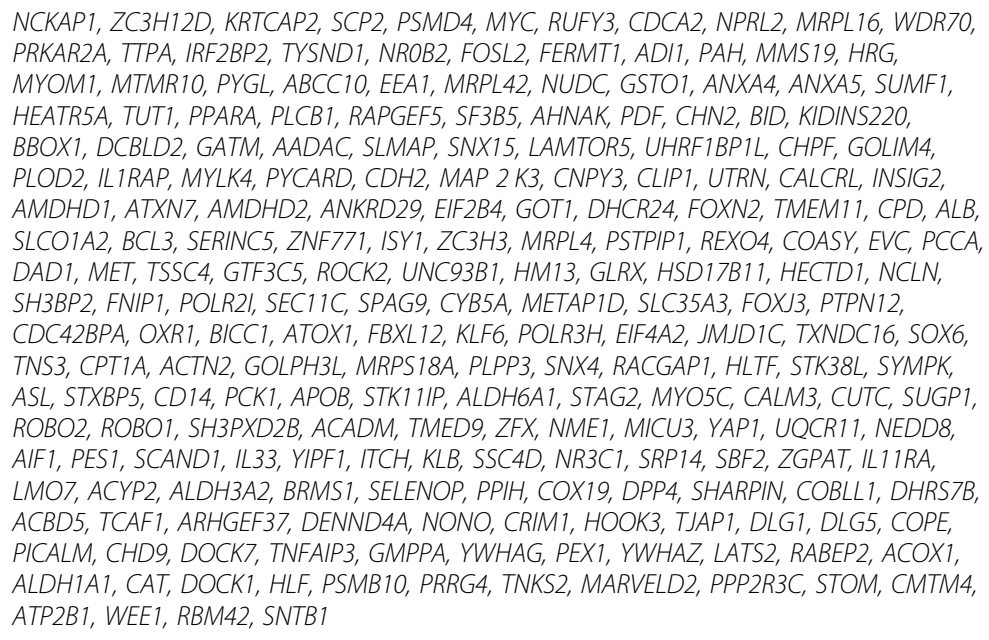 \\
\hline FOXO1 & 181.39 & -36.48 & Inhibited & 10 & $\begin{array}{l}7.35 \mathrm{E}- \\
06\end{array}$ & $\begin{array}{l}1.73 \mathrm{E}- \\
04\end{array}$ & $\begin{array}{l}\text { GMFG, ZC3H12D, IER2, VPS18, HDHD5, RNF125, BIN1, UBA52, RPN1, MCTS1, IRF2BP2, } \\
\text { NR1D2, FOSL2, MMS19, MTMR10, PYGL, ING1, PCMTD1, AEBP2, AHNAK, LAPTM5, LAMTOR5, } \\
\text { FADS2, SMCHD1, TPM1, UTRN, IP6K2, GOT1, RADSA, ISY1, PTPN21, PSTPIP1, DAD1, HM13, } \\
\text { GLRX, MRM1, HECTD1, PTPN18, FOXJ3, KBTBD11, KLF6, NAGK, TRMT61A, TXNDC16, PDK1, } \\
\text { MRPS18A, PLPP3, NEIL1, ZRANB1, STK11IP, STAG2, GUK1, SH3PXD2B, RAC2, ACADM, ZFX, } \\
\text { CD47, PTGER3, SH3BGRL, SSC4D, NR3C1, SRP14, GPRIN3, TYROBP, CCNE2, RPP21, COBLL1, } \\
\text { ECT2, ACBD5, DENND4A, ARHGAP25, GCLM, PICALM, TNFAIP3, PPPIR9B, ADGRE5, USP12, } \\
\text { MAPK6, SNTB1 }\end{array}$ \\
\hline
\end{tabular}

$[57,58]$ until the gluconeogenic response is better developed. Typically, an increase of glucose-6-phosphatase (G6Pase) activity mirrors the decline of hepatic glycogen storage soon after birth [57]. This scenario was confirmed in our experiment by the significant downregulation of GYS2 (Glycogen Synthase 2) [FC = - 1.39] and the simultaneous upregulation of G6PC3 (Glucose-6-Phosphatase Catalytic Subunit 3) [FC = 1.30].

Mechanistically, greater activity of G6P phosphatase favors conversion of glucose-6-phosphate to glucose and ensures the release of glucose into the circulation [59]. Nevertheless, the downregulation of PYGL (Glycogen 
Phosphorylase L) [FC = - 1.32], along with upregulation of NROB2 (Nuclear Receptor Subfamily 0 Group B Member 2) $[\mathrm{FC}=2.64]$ and PPP2R3C (Protein Phosphatase 2 Regulatory Subunit B" Gamma) [FC=1.68] was intriguing. These responses seemed to suggest a better capacity of MET calves in the utilization of lactose for meeting glucose requirements with a consequent reduction in depletion of glycogen reserves. The PYGL gene encodes a protein that catalyzes the cleavage of alpha-1, 4-glucosidic bonds to release glucose-1-phosphate from liver glycogen stores and plays an important role in maintaining blood glucose homeostasis [60]. NROB2 encodes a protein that can directly bind to cAMP response element-binding protein (CREB) to block the association with CREB regulated transcription coactivator 2 (CRTC2), leading to an inhibition of hepatic gluconeogenic mRNA abundance [61,62]. This was in line with the fact that $\mathrm{AKT}$ is known to phosphorylate and inhibit CRTC2 whose disruption is known to improve insulin sensitivity [63]. PPP2R3C encodes a subunit of the PP2A (protein phosphatase 2) holoenzyme involved in glucocorticoid receptor (GR) feedback regulation, and particularly in GR-mediated negative regulation [64]. In this regard, it is known that glucocorticoids in neonatal calves through activation of the GR can influence many important liver functions such as gluconeogenesis [65]. Particularly neonatal glucose metabolism when nutrient supply is insufficient [57]. Overall, this idea was also supported by our metabolomics results. Indeed, in absence of differences in feed intake, the greater concentrations of the tricarboxylic acid cycle intermediates fumarate and glutamate along with NAD/NADH in MET calves indicated enhanced rates of energy metabolism [26].

\section{Lipid metabolism}

Lactose intake on its own is not sufficient to meet glucose demands [56] and mitochondrial FA oxidation increases after birth to cover energy needs [57]. In our experiment, we detected an overall downregulation of 'Lipid metabolism' in MET calves (Fig. 3; Additional File 5), and notably of 'Fatty acid degradation' genes such as ACOX1 (Acyl-CoA Oxidase 1) [FC =1.53], CPT1A (Carnitine Palmitoyltransferase 1A) [FC= - 1.46], and ACADM (Acyl-CoA Dehydrogenase Medium Chain) $[\mathrm{FC}=-1.68]$ all of which are well-known to be crucial for mitochondrial and peroxisomal FA oxidation [66]. There was also a significant downregulation of PPARA (Peroxisome Proliferator Activated Receptor Alpha) [FC $=-1.33$ ] that encodes a nuclear receptor controlling genes required for activation of mitochondrial and peroxisomal FA oxidation [67]. In this context, the downregulation of Gamma-Butyrobetaine Hydroxylase $1(B B O X 1)[\mathrm{FC}=-1.51]$, which in non-ruminants is regulated by PPARA [68], was noteworthy. This gene encodes the rate-limiting enzyme in the synthesis of carnitine from butyrobetaine [68], an essential nutrient for CPT1 activity and mitochondrial FA oxidation $[69,70]$. In the absence of differences in hepatic concentration of butyrobetaine (Table 5) and fat intake, and because calves were consuming a high-fat milk replacer $(15 \%$ crude fat on dry matter basis), the significant upregulation of MCAT (Malonyl-Coa-Acyl Carrier Protein Transacylase) $[\mathrm{FC}=1.42]$ agreed with the downregulation of $C P T 1 A$. Indeed, $M C A T$ is a component of the fatty synthase complex [71] and is specifically involved in the step where malonyl-CoA is loaded into the enzyme complex at the beginning of the FA biosynthesis process [72]. Considering that most of the FA found in the liver would have come as chylomicron remnants or from lipogenesis [73], it is plausible that lipogenesis from intake of lactose and glucose availability in the liver would have increased malonyl-CoA concentration, an allosteric inhibitor of CPT1A and mitochondrial FA oxidation [74]. Although we did not measure proteins involved in mitochondrial or peroxisomal FA oxidation, the downregulation of the above well-known FA oxidation genes that are transcriptionally-regulated suggested that the most logical alternative for the liver to handle FA coming from the diet in the MET calves might have been through synthesis of very low density lipoproteins (VLDL), phospholipid species, and/or incorporation into cellular membranes. The former hypothesis, formulated previously [75], was corroborated in our experiment by the tendency for greater mRNA abundance of MAT1A and PEMT ( $P$ value $<0.10$; Table 7 ) in MET calves. These genes, indeed, play an important role in hepatic phosphatidylcholine (PC) synthesis [76-78], which is known to participate in VLDL synthesis and help prevent fatty liver [79, 80]. Endogenous synthesis of PC from supplemental Met [81] was already proposed to play a role in the ability of the cow liver to handle influx of FA produced from lipolysis after parturition [34]. More in-depth discussion about possible effects on increased VLDL export through the generation of PC is available in Additional File 4.

The marked downregulation of Fatty Acid Desaturase 2 (FADS2) [FC $=-4.02]$ was also intriguing. This gene encodes the delta- 6 desaturase enzyme, which catalyzes the first step in the desaturation and elongation of the dietary essential FA [82]. Interestingly, a different pool of PC molecular species is synthesized in the liver and is partly dependent on the pathway of synthesis: the cytidine diphosphocholine (CDP)-choline and phosphatidylethanolamine $\mathrm{N}$-methyltransferase (PEMT) pathways [83]. PC synthesized via the PEMT pathway has higher concentrations of long-chain and highly-unsaturated species [84], whereas PC produced via the CDP-choline 
pathway has higher monounsaturated and saturated FA [85]. Thus, we speculate that lower FADS2 expression may influence the availability of the preferred substrate required for liver PC synthesis in the PEMT pathway. In this regard, a diminished methylation capacity and hypermethylation silencing of FADS2 mRNA expression has been observed in mice with CBS deficiency [86].

\section{Amino acid metabolism}

Our functional analysis indicated that 'Amino Acid metabolism' was overall inhibited (Fig. 3; Additional File 5), due to marked inhibition of the 'Valine, leucine and isoleucine degradation' pathway. Leucine, isoleucine and valine are branched-chain amino acids (BCAA) with a number of biological functions beyond protein synthesis [87]. Furthermore, although little is known about the impact of changes in BCAA availability on immune system functionality in ruminants, both human and rodent studies have underscored the relationship between BCAA availability and improved immune function [8891], highlighting the need for further studies about BCAA effects on dairy cows during the periparturient period and on newborn calves.

An increased concentration and utilization of essential AA, particularly BCAA, was observed in immortalized bovine mammary epithelial cells when the supply of Met increased [92]. The authors speculated this change was potentially mediated by alterations in AA transporters controlled by mTOR whose activation was observed when Met supply increased [92-94]. In this context, the significant upregulation of Late Endosomal/Lysosomal Adaptor, MAPK and MTOR Activator (LAMTOR2) $[\mathrm{FC}=1.36]$ was noteworthy. The protein encoded by this gene is part of the regulatory complex involved in AA sensing and activation of mTORC1 [95], a signaling complex promoting cell growth in response to growth factors, energy level, and supply of AA [96].

Although a greater mRNA abundance of AA transporters was observed in the placenta of MET cows [24], which we speculated was partly due to greater DMI, overall, our results indicated that feeding RPM to enhance post-ruminal supply of MET did not affect hepatic AA transport in calf liver. In this regard, it is important to note that our calves were fed a high-protein milk replacer (28\% crude protein on dry matter basis). Without differences in intake, our results suggested a lower utilization of AA in MET calf liver. This idea is supported by the lower $\mathrm{p}$-S6K1, since it is well known the central role played by $\mathrm{S} 6 \mathrm{~K} 1$ in the regulation of protein translation in mammals [97]. The numerically-lower expression of pRPS6 $(P$ value $=0.15)$ also partly corroborated this idea. Indeed, RPS6 was the first S6K substrate identified [98]. Considering our scenario of lower AA utilization by the liver, we speculate about the presence of possible AA 'sparing effects' in MET calves, i.e. more essential AA available for other organs, e.g. skeletal muscle for growth. This hypothesis agrees with the greater rate of growth already observed in utero and during early postnatal life in calves born to cows fed RPM to enhance post-ruminal Met supply during late gestation $[26,27]$.

\section{Glutathione metabolism}

Although no significant differences between $\mathrm{CON}$ and MET calves were detected for GSH concentration, upregulation of GSTO1 (Glutathione S-Transferase Omega 1) $[\mathrm{FC}=2.85]$ and GPX1 (Glutathione Peroxidase 1) [FC = 1.56; Additional File 2] both of which are involved in 'Glutathione metabolism' underscored the importance of this pathway in the MET neonatal liver. In nonruminants, the role of GSH (a potent intracellular antioxidant in liver tissue) has been extensively described, in particular its association with methyl-transferase products involved in 'Cysteine and Methionine metabolism' [99]. In this regard, the tendency for greater taurine production in MET calves ( $P$ value $=0.06$; Table 3 ) suggested possible beneficial effects on antioxidant responses during early postnatal life. An improved antioxidant status has been observed in peripartal dairy cows receiving enhanced post-ruminal Met supply [22, 35], and an increased in GPX activity also has been highlighted [100].

The idea that endogenous taurine plays a role in the antioxidant response of calves was formulated considering enzyme activity and metabolomics in the bigger cohort of calves from the present study [26]. It was further supported by data from an in vitro study in which taurine supplementation mitigated the inflammatory activation of blood polymorphonuclear leukocytes from neonatal Holstein calves [101]. More in general along with taurine, despite the lower CBS activity, the greater concentration of cystathionine and serine detected in MET calves suggested a greater activity of the transsulfuration pathway in MET calves, which is the main source of the cellular antioxidant GSH [40]. This scenario in our experiment supported the hypothesis of a better antioxidant status in MET calves, also suggested by the marked downregulation of Catalase (CAT) [FC = - 1.77; Additional File 2]. In humans, CAT is the mostadaptive antioxidant enzyme in the presence of oxidative stress and plays a pivotal role in cellular defense against oxidative damage [102].

The increase of antioxidant enzymes such as CAT can be considered a compensatory response to increased oxidative stress [103]. In non-ruminants, hepatic CAT activity increased during oxidative impairment due to an inhibition of CBS, although no variation in mRNA abundance [104] and no effect on GHS peroxidase, GHS 
reductase and GHS S-transferase activities were reported [104]. This latter pattern seemed to be recognizable in our experiment, suggesting that lower CBS activity was not associated with an alteration in epigenetic methylation as reported previously [105]. This is particularly noteworthy considering the role played by CBS in the transition from methylation to transsulfuration. More in-depth discussion about CBS activity is available in Additional File 4.

Overall, our results seemed to support the idea that feeding RPM to enhance post-ruminal supply of Met (along with other nutrients due to the greater DMI) may promote, through the transsulfuration pathway, production of the antioxidants GSH and taurine in calves [26]. The increased potential for antioxidant production may help alleviate oxidative stress and inflammation induced from reactive oxygen metabolite production in the liver $[35,106,107]$ particularly at birth when antioxidant mechanisms in the new-born are still immature [108, 109]. Although downregulation of various genes associated with mitochondrial FA oxidation was observed in MET calves, the fact that high intracellular levels of FA are a source of reactive oxygen species [110] potentially via peroxisomal oxidation underscores the importance for production of antioxidants such as GSH and taurine. This hypothesis was also broadly supported in our experiment by the marked downregulation of 'p53 signaling pathway' (Fig. 5), since it is known that p53 activation is induced by multiple stress signals [111] and notably by oxidative stress [112].

Furthermore, considering that induction of thermogenic genes was recently observed as a consequence of taurine supplementation [113], and that liver is one important hub in thermogenesis [114], the overall upregulation of 'Enrivonmental Adaptation' function (Fig. 3; Additional File 5) due to changes in the 'Thermogenesis' pathway suggested that adaptive functions also might have been enhanced by feeding RPM to enhance postruminal supply of Met in the pregnant cow. The importance of thermoregulation in the newborn is wellestablish as well as its linkage with energy sources available at birth [115], thus, it is plausible that a better energetic and immunometabolic status in MET calves may contribute to the thermoregulation.

\section{Immune system}

New-born calves are immunologically naïve at birth [116], and particularly vulnerable since they have to face many stressors while their immune system is still immature [33]. Birth is the first direct and critical stressor in the calf's life that has to be faced through innate immunity, a process that functions less effectively in adults, and passive immunity, i.e. the ingestion of colostrum [116]. In this regard, it is worth noting that feeding RPM in late-pregnancy does not seem to impact colostrum yield, colostral FA or AA profiles, colostral immunoglobulin G (IgG) concentrations, or apparent IgG absorption by the calf $[27,30]$, suggesting that neither the increase in postruminal Met nor total nutrient supply (due to greater DMI) affects the ability of the calf to acquire passive immunity. This is in line with the absence of difference in plasma GGT concentration in MET or CON calves (Table 2). Activity of GGT is a suitable indicator of passive immunity transfer in calves, and is highly- and positively-correlated with plasma IgG [117]. At least in non-ruminants, the liver is a key frontline immune tissue, balanced between an anti-inflammatory and immunotolerant status $[118,119]$. In our study the overall upregulation of various pathways involved in 'Immune system' (Fig. 3; Additional File 5) and notably of 'C-type lectin receptor signaling' and 'Natural killer cell mediated cytotoxicity' pathways (Fig. 4) seemed to support our general hypothesis of an enhanced immunometabolic status in response to feeding RPM to enhance post-ruminal supply of Met in late-pregnancy. Indeed, these pathways are well-known to be involved in innate immunity [120-122].

The upregulation of the 'Natural killer cell mediated cytotoxicity' pathway was especially noteworthy considering that natural killer cells are mainly present in liver tissue and play a key role in the innate immune system [121, 123, 124]. Increasing evidence of cross talk between NK cells and other immune cells suggested that NK cells also play an important role in shaping the adaptive immune response [125-127]. On the other hand, C-type lectin receptors (CLR) are powerful pattern-recognition receptors that mediate immune recognition and response [128], whose role in orchestrating the induction of signaling pathways regulating adaptive immune responses is also well-recognized $[129,130]$.

The evident upregulation of the 'Glycan Biosynthesis and Metabolism' pathway (Fig. 3) agreed with the general scenario of an earlier and more effective immune status. Indeed, the role of glycans in the regulation of both innate and adaptive immune responses is welldocumented in non-ruminants [131], in particular it is well-known that the immune system is highly controlled and fine-tuned by glycosylation through the addition of a diversity of carbohydrate structures (glycans) to the immune cell receptors [131]. This was consistent with the upregulation of the ' $\mathrm{C}$-type lectin receptor signaling' pathway in our experiment, since C-type lectins are a class of glycans binding proteins [132]. In addition, considering the role of the phagosome in linking innate and adaptive immunity [133], the upregulation of the 'Phagosome' pathway (Fig. 4) also supported the hypothesis of an enhanced immune status in MET calves. 
The general downregulation of 'Platelet activation' (Additional File 5) broadly agreed with this scenario, since liver dysfunction is usually reported in combination with an activation of platelets, often considered dynamic sentinels interacting with immune cells [134136]. In this context, the marked upregulation of $M$ SAA3.2 (Mammary Serum Amyloid A3.2) [FC=5.70] was noteworthy (Table 8 ). SAA is an acute-phase protein which is highly-conserved among all vertebrate species [137]. In this regard, it is important to note that, if this response translated into more SAA protein secreted from the liver, it would mean that AA within liver would have been channeled away from protein synthesis, as suggested by the lower p-S6K1 observed in MET calves. Although the functional significance of SAA production remains speculative, several authors suggested its plausible role as an immunological defense molecule providing immediate defense against inflammatory challenges [138, 139], with a protective role during inflammation [140] and particularly with a possible beneficial function in the well-being and better extrauterine life adaptation in calves [141]. More in-depth discussion on single target genes involved in the general context of enhanced immune status is available in Additional File 4.

\section{Upstream regulators}

Transcription factor enrichment analysis with the ChEA3 tool [142] allowed us to predict 72 TF significantly associated (FDR $\leq 0.05$ ) with our DEG list (Additional File 3). A similar approach to the DIA analysis [143] was also applied to predict the potential impact and flux for each highlighted TF. Focusing on the top-10 ranked TF (Table 10) and based on information retrieved from the published literature, many of them are consistent with our general scenario of a higher immunometabolic state, greater insulin sensitivity and lower mitochondrial FA oxidation in MET calves. Among other TF identified were FOXO1 (Forkhead Box O1), PPARG (Peroxisome Proliferator Activated Receptor Gamma), E2F1 (E2F Transcription Factor 1), and CREB1 (CAMP Responsive Element Binding Protein 1). All these have relatively well-established associations with important metabolic and cellular processes in nonruminants.

At least in non-ruminants, FOXO1 is a key TF associated with coordinating lipid metabolism in the postabsorptive state, integrating insulin signaling with glucose and lipid metabolism [144]. In liver, insulin activates the PI3K/PKB signaling pathway [145] and results in FOXO1 protein phosphorylation and degradation [146]. FOXO1 binds and promotes transcription of PCK1, which plays a key role in gluconeogenesis [146]. Indeed, hepatic FOXO1 loss-of-function mutant suppresses PCK1 expression determining a decreased hepatic gluconeogenesis [146]. Also the regulation of pyruvate dehydrogenase kinase (PDK) expression by FOXO signaling has been recently investigated and the inhibition of PDK by insulin via phosphorylation of FOXO through PI3K/Akt signaling pathway has been described $[147,148]$. The downregulation of PDK1 [FC= -1.45] in our experiment was in line with this scenario. Furthermore, at least in non-ruminants, FOXO1 regulates transcription of genes involved in hepatic assembly of VLDL [149] and also plays a fundamental role in development and differentiation of immune cells [150].

The nuclear receptor PPARG belongs to peroxisome proliferator-activated receptors, members of the superfamily of ligand-activated nuclear transcription factors. Many PPAR-regulated genes encode proteins that regulate FA oxidation (mitochondrial and peroxisomal) and storage, for example, $A C O X 1$ and $C P T 1 A$. Furthermore, PPARG regulates pantothenate kinase (PANK) [151], which catalyzes the rate-controlling step in coenzyme A (CoA) biosynthesis [152]. In our experiment, we detected downregulation of PANK3 [FC $=-1.87$ ], which would be metabolically important because CoA is an essential cofactor supporting a multitude of oxidative and synthetic reactions, including those involved in FA biosynthesis and oxidation [153]. Taking all of this into account, the predicted inhibition of PPARG seemed particularly in line with our general scenario of FA oxidation downregulation.

Among the list of top-10 ranked TF, the presence of E2F1, a well-known TF promoting hepatic gluconeogenesis [154] and innate immune response [155] is noteworthy. Similarly, the predicted activation of CREB1 whose role in coordinating hepatic lipid and glucose metabolism through inhibition of PPARG has been documented [156] along with its role in the immune system through promoting anti-inflammatory responses [157].

\section{Conclusions}

Feeding RPM to enhance maternal post-ruminal Met supply was associated with greater global DNA methylation and distinct hepatic transcriptome, proteome, and metabolome profiles after birth. The hypothesis that enhancing post-ruminal Met supply during late-gestation primed or programmed the Met cycle in calf liver was corroborated. However, in light of the greater DMI in response to feeding RPM (a consistent response across published studies), the increased supply of other nutrients and their potential impact cannot be disregarded. Molecular changes with potential beneficial effects to overall hepatic function were highlighted, especially in terms of metabolism and inflammatory status. This was attributable to the change in expression profiles of several genes mainly involved in 'Glucose', 'Lipid', 'Glutathione', and 'Immune System' metabolism. In particular, 
the results seemed to suggest a greater flux through the TCA cycle along with a better antioxidant status due to taurine and GSH synthesis. Although further studies are required to corroborate this result, the upregulation of 'Immunity System' pathways supported the hypothesis that feeding RPM to enhance maternal Met supply may play a role in regulating fetal immunity.

\section{Methods}

\section{Animals}

All procedures for this study were conducted in accordance with a protocol approved by the Institutional Animal Care and Use Committee (IACUC) of the University of Illinois (protocol \# 14270). Heifer calves in the present study were a subset from a larger cohort of animals born to Holstein cows randomly assigned to receive a basal control (CON) close-up diet (from - $28 \pm 2 \mathrm{~d}$ to parturition) $[1.47 \mathrm{Mcal} / \mathrm{kg}$ dry matter (DM) and $15.3 \%$ crude protein $(\mathrm{CP})$ ] with no added Met or CON plus ethyl cellulose MET (MET, Mepron ${ }^{\bullet}$ Evonik Nutrition \& Care GmbH, Germany) [27]. Diet composition is available in Additional File 6. All management procedures have been described previously [27]. Briefly, during the preliminary period from -45 to -29 d relative to parturition all cows received a common low-energy and high-straw far-off diet $(1.33 \mathrm{Mcal} / \mathrm{kg}$ of $\mathrm{DM}$ and $13.9 \%$ CP) with no RPM. Cows were individually-fed using Calan gates (American Calan Inc., Northwood, $\mathrm{NH}$ ). At - 28 days relative to parturition, cows were randomly assigned to CON or MET groups. The Met product was offered at a rate of $0.09 \%$ of previous day DMI. This supply of Met was based on studies demonstrating beneficial effects on production performance and health during the prepartum period [23, 158]. Mepron ${ }^{\circ}$ is a commercial rumen-protected source of DL-Met in the form of small beads containing a minimum of $85 \%$ methionine that resists ruminal degradation due to an ethyl-cellulose film coating the methionine core. The intestinal digestibility coefficient of Mepron ${ }^{\circ}$ is 90\% [159] and its ruminal bypass value is $80 \%$ [160]. Feeding this amount of RPM increased Met concentrations in plasma prior to and during the first 3 weeks postpartum [25].

After parturition, neonatal calves were separated from their dams. Body weight (BW), hip and wither height $(\mathrm{HH}, \mathrm{WH})$, hip width $(\mathrm{HW})$ and body length were measured. Heifer calves were kept in the experiment if they fulfilled all the following criteria previously described [30], 1) single heifer calf; (2) heifer calf birth weight $>36$ $\mathrm{kg}$; (3) calving difficulty score $<3$; and (4) dam first colostrum volume $>3.8 \mathrm{~L}$. All calves were managed in the same fashion. At birth, the navel was disinfected with $7 \%$ tincture of iodine solution (First Priority Inc., Elgin, IL, United States), and neonatal calves were vaccinated with
TSV II (Pfizer Inc., New York, NY, United States) via nostril application.

Calves were offered $3.8 \mathrm{~L}$ of first milking colostrum from their mother within $6 \mathrm{~h}$. If voluntary colostrum intake had not reached the $3.8 \mathrm{~L}$ required, calves were force-fed via an esophageal tube to ensure that all calves consumed the same amount of colostrum. Calves were housed in individual outdoor hutches bedded with straw and fed twice daily (AM and PM) with a milk replacer (Advance Excelerate, Milk Specialties, Carpentersville, IL; $28.5 \%$ CP, $15 \%$ fat). More in detail, heifer calves received $4.54 \mathrm{~kg} /$ day of milk replacer mix $(0.59 \mathrm{~kg}$ of milk replacer in $3.95 \mathrm{~L}$ of water) and had ad libitum access to starter grain mix [Ampli-Calf Starter $20^{\circ} ; 19.9 \% \mathrm{CP}$ and 13.5\% neutral detergent fiber (NDF), Purina Animal Nutrition, Shoreview, MN, United States] fed in the morning. All heifer calves remained clinically healthy during the study.

\section{Sample collection}

Per IACUC guidelines, blood samples were collected ( $n=6$ calves per group) from the jugular vein at $2 \mathrm{~d}$ of age using 20-gauge BD Vacutainer needles (Becton Dickinson, Franklin Lakes, NJ). Vacutainer tubes used contained lithium heparin, and plasma was obtained by centrifugation at $1900 \times \mathrm{g}$ for $15 \mathrm{~min}$ at $4{ }^{\circ} \mathrm{C}$ and stored at $-80^{\circ} \mathrm{C}$ until further analysis. Plasma was used to analyze the concentrations of a number of biomarkers associated with energy metabolism (e.g. NEFA, BHBA), immune function, liver function, and oxidant status according to protocols described in a number of publications from our group [9, 10, 30, 31]. In addition, plasma was used to profile concentrations of free $\mathrm{AA}$ and indicators of skeletal muscle protein turnover [27]. Plasma insulin concentrations were determined using a bovine-specific commercial ELISA kit (catalog no. 10-1201-01; Mercodia, Uppsala, Sweden).

Per IACUC guidelines, surgical biopsies of the liver could not be obtained until day 4 of age. At that point, samples were obtained via puncture biopsy under local anesthesia ( $\mathrm{n}=6$ calves per group) using published protocols from our group $[26,31]$. Tissue was frozen immediately in liquid nitrogen and stored at $-80{ }^{\circ} \mathrm{C}$ until further analysis. Samples from the same calves $(n=6$ per treatment) used for DNA methylation and RNAsequencing were used for protein expression, enzyme activity, and metabolomics analyses. The chosen protein targets are key members of the nutrient signaling cascades that respond to insulin and AA supply, hence, allowed us to evaluate potential effects of maternal MET on key metabolic aspects of neonatal liver function. Since newborn calves do not have a functional rumen, insulin plays an essential role on aspects of hepatic nutrient metabolism including coordination of glucose, FA, 
and AA metabolism [57]. Similarly, since our previous work with neonatal calves revealed unique adaptations in hepatic one-carbon metabolism in response to feeding RPM in late-pregnancy $[10,30]$, we elected to perform those assays along with targeted metabolomics analysis.

\section{DNA isolation and global DNA methylation}

The DNA was isolated from $50 \mathrm{mg}$ of liver tissue using the Blood and Tissue DNeasy Kit (Qiagen). Methylation of genomic DNA was detected using the Methylamp global DNA methylation quantification ultra-kit (Epigentek) according to manufacturer's instructions. Details on calculation were reported previously by our group [161].

\section{Western blotting}

The protocol used for western blot was the same as reported previously [162]. Briefly, $50 \mathrm{~g}$ of liver tissue was used for total protein extraction using T-PER tissue protein extraction reagent (Cat. 78,510, Thermo Scientific) containing Halt protease and phosphatase inhibitor cocktail (100x, catalog no. 78442; Thermo Fisher Scientific). Concentration of total protein was determined using the Pierce BCA protein assay kit (catalog no. 23227; Thermo Fisher Scientific). Equal amounts of protein were separated using 4-20\% Mini-Protean TGX precast gels (Cal. 4,561,096, Bio-rad) and transferred onto a PVDF membrane (Cat. 1,620,261, Bio-rad) using a semidry transfer cell (Serial No. 221BR, Bio-rad). After blocking with $5 \%$ non-fat dry milk in trisbuffered saline at room temperature for $2 \mathrm{~h}$, the membrane was washed and incubated with a primary antibody directed against target antibodies. Antibodies raised from rabbit monoclonal antibody were from Cell Signaling Technology and diluted to 1:1000 prior to use [25, 92]. Targets were mTOR, p-mTOR (Ser2448), S6K, p-S6K (Thr389), RPS6, p-RPS6 (Ser235/236), 4EBP1, p-4EBP1 (Thr37/46), Akt, p-Akt (Ser473), eIF2, p-eIF2 (Ser51), eEF2, and peEF2 (Thr56) (catalog nos. 2972, 2971, 9202, 9234, 2217, 2211, 9452, 9459, 9272, 9271, 9722, 9721, 2332, and 2331, respectively; Cell Signaling Technology). The secondary antibody was HRP AffiniPure goat anti-rabbit IgG (ab6721, Abcam, diluted to 1:10,000). Visualization of the target proteins was performed using the Clarity Western ECL Substrate (Cat. 170-5060, Bio-rad). Each protein was normalized against GAPDH (Polyclonal antibodies raised in rabbit, ab22555, Abcam, diluted 1: 2000). Data are reported as relative expression. The ECL signals were recorded using an imaging system (ChemiDocTM MP, Bio-rad) and analyzed using Image lab 5.2.1 (Bio-Rad, USA).

\section{Metabolomics}

Approximately $100 \mathrm{mg}$ of frozen tissue was extracted using a 2-step protocol described by Wu et al. [163].
Targeted metabolomics (liquid chromatography-MS) was performed to quantify 31 metabolites related to TCA cycle, one-carbon metabolism, and transsulfuration pathway. Samples were analyzed with the 5500 QTRAP liquid chromatography-tandem MS system (Sciex, Framingham, MA) at the metabolomics core facility of the Roy J. Carver Biotechnology Center, University of Illinois (Urbana). Software Analyst 1.6.2 [161] was used for data acquisition and analysis.

\section{One-carbon metabolism enzyme activity assays}

Activity of BHMT, MTR, and CBS was determined according to protocols detailed by Zhou et al. [164].

\section{RNA extraction and quantitative PCR}

All RNA extraction procedures were performed as described previously [26]. Briefly, RNA extracted from liver samples using the miRNeasy kit (Qiagen, Hilden, Germany) following the manufacturer's protocol. Samples were treated on-column with DNaseI (Qiagen) to remove genomic DNA from the RNA. Quantification was accessed using the NanoDrop ND-1000 (NanoDrop Technologies, Rockland, DE), and RNA quality was measured using an Agilent 2100 Bioanalyzer (Agilent, Santa Clara, CA). All samples had an RNA integrity number factor greater than 8, RNA was diluted to $100 \mathrm{ng}$ with DNase/RNase-free water for cDNA synthesis by using RT-PCR, and the cDNA was diluted 1:4 with DNase/ RNase-free water.

The quantitative PCR (qPCR) performed was SYBER Green based (Quanta Biosciences, Beverly, MA), using a 7-point standard curve obtained from a cDNA pool of all samples. The final data were normalized using the geometric mean of 3 internal control genes: UXT, GAPDH, and RPS9. A total of 24 genes selected related to the Met cycle, DNA methylation, transsulfuration, GSH, and cytidine $5^{\prime}$-diphosphocholine (CDP)-choline pathway were measured. The $\log _{2}$ transformed data were analyzed in order to compare the expression means of CON and MET groups. All evaluated genes and primer information are reported in Additional File 7.

\section{Statistical analysis}

Data were assessed for normality of distribution using the Shapiro-Wilk test. When the normality assumption was rejected, data were $\log _{2}$-transformed before statistical analysis and $\log _{2}$-back transformed after analysis. Differences between the means of the groups were analyzed via one-way ANOVA. Statistical differences were declared significant at $P$ value $\leq 0.05$ and tendencies at $P$ value $\leq 0.10$. All statistical analyses were performed in $R$ environment [165]. 


\section{RNA-sequencing}

Sequencing was performed by the High-Throughput Sequencing and Genotyping Unit of the W. M. Keck Biotechnology Center at the University of Illinois at Urbana Champaign (Urbana, IL, USA). A total of 12 mRNA libraries were prepared with Illumina's 'TruSeq Stranded Sample Prep kit' following the manufacturer's instructions. Libraries were sequenced on one lane for $101 \mathrm{cy}-$ cles from one end of the fragments on a HiSeq2500 (Illumina Inc.), using HiSeq SBS sequencing kit version 4. Fastq files were generated and demultiplexed with the bcl2fastq (v2.17.1.14) software (Illumina). Approximately a total of 143 million single-reads sequences of $100 \mathrm{nt}$ in length were collected. The quality control of the raw sequences was assessed with FastQC software (v0.11.15) and the reads were mapped to the bovine reference genome (UMD v.3.1.1; Ensembl Genomes website) using the software package STAR (v2.5.3a). The number of reads that mapped to each gene in each sample was calculated using the feature Counts function in the Subread package (v1.5.2). Data are available at the GEO site of NCBI (GSE163644).

\section{Identification of differentially expressed genes}

The entire downstream analysis for identification of DEGs was conducted within the $\mathrm{R}$ environment using the edgeR pipeline [166]. Non-expressed and weaklyexpressed genes were removed [167], TMM (trimmed mean of $\mathrm{M}$-values) normalization was applied to all samples and the data were $\log _{2}$-transformed. Once dispersion estimates were obtained and a negative binomial generalized linear model was fitted with a design matrix describing the treatment condition (MET and CON groups), quasi-likelihood F-test was used to determine differential expression. Multiplicity correction was performed by applying the BenjaminiHochberg method on the $P$ values, to control the false discovery rate (FDR). The expression level was deemed to be significantly different between the two groups for FDR $\leq 0.10$ [32].

\section{Dynamic impact approach (DIA)}

The DIA software was used for functional analyses [143]. Briefly, DIA uses the KEGG systems information to rank biological pathways, calculating the overall impact (importance of a given pathway) and flux (direction of impact; e.g., upregulation, downregulation, or no change) based on gene fold change (FC) values. For this purpose, the entire DEG data set $(\mathrm{FDR} \leq 0.10)$ with associated statistical $P$ values was imported into DIA and the functional analysis was performed interrogating all KEGG pathway database.

\section{Gene network analysis}

The PANEV (Pathway Network Visualizer) tool [168] was extensively used to visualize the results in a context of gene/pathway networks, and pinpoint candidate genes associated with a subset of pathways of interest. Briefly, PANEV is an R package set for gene/pathway-based network visualization. Based on information available on KEGG, it visualizes genes within a customized network of multiple interconnected pathways, chosen by the user since supposed to be involved with the trait under investigation. The network graph visualization helped us to interpret functional profiles of cluster of genes. In our case, a network of interconnected (i.e. up- and downstream) pathways involved in 'Glycolysis/gluconeogenesis', 'Lipid metabolism', 'Amino acid metabolism' and 'Immune system' pathways was created to pinpoint functional candidate genes with coordinate expressions (Additional File 8).

\section{Transcription regulator discovery}

ChIP-X Enrichment Analysis 3 (ChEA3) tool [142] was used to predict the TF associated with the downstream DEG. ChEA3 is a transcription factor enrichment analysis software that ranks TF associated with usersubmitted gene sets [142]. The entire list of DEG (FDR $\leq$ 0.10) was uploaded on ChEA3 and the 'Literature ChIPseq' library, containing ChIP-seq experiments from human, mouse and rat, was interrogated. ChEA3 core analysis was run using default settings and TF with FDR $\leq$ 0.05 were considered significantly associated with our DEG list. Furthermore, in order to estimate the state (i.e. activation/inhibition) of significantly-predicted TF, the same approach underlying DIA analysis [143] was applied to the candidate TF list. Briefly, impact and flux value were calculated for each predicted TF according to Bionaz et al. [143]: the impact was obtained by combining the proportion of DEG with the $\log _{2}$ mean fold change and mean - $\log \mathrm{P}$ value of all TF-target genes. More details about rationale and calculation steps of the analysis are reported in the original publication [143]. The ChEA3 outcomes were matched with PANEV results in order to create a network of possible connections between TF and the downstream DEG involved with the 'Glycolysis/gluconeogenesis', 'Lipid metabolism', 'Amino acid metabolism' and 'Immune system' pathways (Additional File 9).

\section{Abbreviations}

4EBP1: Eukaryotic translation initiation factor 4E-binding protein 1; AA: Amino acid; ACADM: Acyl-CoA dehydrogenase medium chain; ACOX1: Acyl-CoA oxidase 1; AKT: Serine/threonine-protein kinases; AM: Ante meridiem; ANGP

TL3: Angiopoietin-like protein 3; ANOVA: Analysis of variance; APOB: Apolipoprotein B; BBOX1: Butyrobetaine hydroxylase 1;

BCAA: Branched-chain amino acids; BHBA: Beta-hydroxybutyric acid; BHMT: Betaine-homocysteine S-methyltransferase; BW: Body weight; CAT: Catalase; CBS: Cystathionine $\beta$-synthase; CCNB1: Cyclin B1; CD14: CD14 
molecule; CD209: CD209 molecule; CDK1: Cyclin-dependent kinase 1; CDNA: Complementary deoxyribonucleic acid; $C D O 1$ : Cysteine dioxygenase type 1; CDP: Cytidine diphosphate; ChEA3: ChIP-X enrichment analysis 3; CLEC6A: C-type lectin domain containing 6A; CLR: C-type lectin receptors; CON: Control; CPT1A: Carnitine palmitoyltransferase 1A; CREB1: CAMP responsive element binding protein 1; CRTC2: CREB regulated transcription coactivator 2; DEG: Differentially expressed gene; DIA: Dynamic impact approach; DMI: Dry matter intake; DNA: Deoxyribonucleic acid; dTMP: Deoxythymidine monophosphate; dUMP: Deoxyuridine monophosphate; E2F1: E2F transcription factor 1; ECL: Emitter-coupled logic; eEF2: Eukaryotic elongation factor 2; elF2: Eukaryotic initiation factor 2; FA: Fatty acid; FADS2: Fatty acid desaturase 2; FDR: False discovery rate; FOXO1: Forkhead transcription factor 1; FOXO4: Forkhead box O4; G6Pase: Glucose-6-phosphatase; G6PC3: Glucose-6-phosphatase catalytic subunit 3; GAPDH: Glyceraldehyde-3-phosphate dehydrogenase; GCL: Glutamate-cysteine ligase; GCLM: Glutamate-cysteine ligase modifier subunit; GPX1: Glutathione peroxidase 1; GR: Glucocorticoid receptor; GSH: Glutathione; GSK3: Glycogen synthase kinase 3; GSTO1: Glutathione Stransferase omega 1; GYS2: Glycogen synthase 2; HH: Hip height; HIST1H2AC: H2A clustered histone 6; HRP: Horseradish peroxidase; HW: Hip width; IACUC: Institutional animal care and use committee; IgG: Immunoglobulin G; INSIG2: Insulin induced protein 2; KEGG: Kyoto encyclopedia of genes and genomes; KLF5: Krüppel-like factor 5; LAMTOR2: Late endosomal/lysosomal adaptor, MAPK and MTOR activator; LIPH: Lipase H; LPA: Lipoprotein A; LPL: Lipoprotein lipase; MAPK: Mitogenactivated protein kinase; MAT1A: Methionine adenosyltransferase 1A; MAT2B: Methionine adenosyltransferase 2B; MCAT: Malonyl-CoA-acyl carrier protein transacylase; Met: Methionine; MET: Maternal methionine supplied; mRNA: Messenger ribonucleic acid; M-SAA3.2: Mammary serum amyloid A3.2; mTORC1: Mechanistic target of rapamycin kinase 1; MTR: 5-

methyltetrahydrofolate homocysteine methyltransferase; NAD: Nicotinamide adenine dinucleotide; NADH: Nicotinamide adenine dinucleotide plus hydrogen; NDF: Neutral Detergent Fiber; NEFA: Non-esterified fatty acids; NK: Natural killer; NROB2: Nuclear receptor subfamily 0 group B member 2; NR3C1: Nuclear receptor subfamily 3 group $C$ member 1; p-

4EBP1: Phosphorylated eukaryotic translation initiation factor $4 \mathrm{E}-$ binding protein 1; p-AKT: Phosphorilated serine/threonine-protein kinases; PANEV: Pathway network visualizer tool; PANK: Pantothenate kinase; PC: Phosphatidylcholine; PCK1: Phosphoenolpyruvate carboxykinase 1; PCYT1B: Phosphate cytidylyltransferase 1, choline, beta; PDK: Pyruvate dehydrogenase kinase; p-eEF2: Phosphorylated eukaryotic elongation factor 2; p-elF2: Phosphorylated eukaryotic initiation factor 2;

PEMT: Phosphatidylethanolamine N-methyltransferase; Phe: Phenylalanine; PI3K: Phosphoinositide 3-kinases; PKB: Protein kinase B; PLPP3: Phospholipid phosphatase 3; PM: Post meridiem; p-mTOR: Phosphorylated mechanistic target of rapamycin kinase.; POLR2I: RNA polymerase II subunit l;

POLR3H: RNA polymerase III subunit H; PP2A: Protein phosphatase 2; PPARA: Peroxisome proliferator activated receptor alpha; PPARG: Peroxisome proliferator sctivated receptor gamma; PPP2R3C: Protein phosphatase 2 regulatory subunit B" gamma; p-RPS6: Phosphorylated ribosomal protein S6; p-S6K1: Phosphorylated ribosomal protein S6 kinase beta-1; PYGL: Glycogen phosphorylase L; GPCR: Quantitative polymerase chain reaction;

QTRAP: Quadropule ion trap; REC8: REC8 meiotic recombination protein; RNA: Ribonucleic acid; RNA-Seq: RNA sequencing; RPM: Rumen-protected methionine; RPS6: Ribosomal protein S6; RPS9: Ribosomal protein S9; RTPCR: Real-time polymerase chain reaction; S6K: Ribosomal S6 kinase; S6K1: Ribosomal protein S6 kinase beta-1; SAM: S-adenosylmethionine; SCAP: SREBP cleavage-activating protein; SLC44A4: Solute carrier family 44 member 4; SLC51A: Solute carrier family 51 subunit alpha; SREBP 1: Sterolregulated element-binding protein; SREPB1c: Sterol regulatory element binding transcription factor 1c; Tau: Taurine; TCA: Tricarboxylic acid cycle; TF: Transcription factor; THF: Tetrahydrofolate; TNF: Tumor necrosis factor; TRMT61A: tRNA methyltransferase 61A; TYMS: Thymidylate synthase; UXT: Ubiquitously expressed prefoldin like chaperone; VLDL: Very low density lipoproteins; WH: Wither height

\section{Supplementary Information}

The online version contains supplementary material available at https://doi. org/10.1186/s12864-021-07538-w.
Additional File 1: Summary of RNA sequencing and alignment for all the samples. mRNA libraries were sequenced on a HiSeq2500 (Illumina Inc.). Quality control metrics were performed on raw sequencing reads using the FASTQC (v0.11.15) application. An index of the reference genome was built and single-end clean reads for each individual were aligned to the reference genome by STAR (v2.5.3a). Reads were mapped and annotated to the Bos Taurus UMD 3.1.1, downloaded from Ensembl Genomes website. Reads aligned were quantified with Subread package (v1.5.2) based on the Refseq gene annotation.

Additional File 2: List of all differentially expressed genes (FDR $\leq 0.10$ ) from RNAseq data in liver tissue of 4-d old Holstein calves ( $n=6 /$ group) born to cows randomly assigned to receive a basal control (CON) diet from $-28 \pm 2 \mathrm{~d}$ to parturition [1.47 Mcal/kg dry matter (DM) and 15.3\% crude protein (CP)] with no added Met or CON plus ethyl cellulose Met (MET, Mepron ${ }^{\oplus}$, Evonik Nutrition \& Care GmbH, Germany).

Additional File 3: List of all transcription factor (TF) obtained with ChEA3 transcription factor enrichment analysis tool and significantly overrepresented $(F D R \leq 0.05)$ in the differentially expressed gene $(D E G)$ list from RNAseq data in liver tissue of 4-d old Holstein calves $(n=6 /$ group) born to cows randomly assigned to receive a basal control (CON) diet from $-28 \pm 2 \mathrm{~d}$ to parturition $[1.47 \mathrm{Mcal} / \mathrm{kg}$ dry matter (DM) and $15.3 \%$ crude protein (CP)] with no added Met or CON plus ethyl cellulose Met (MET, Mepron ${ }^{\oplus}$, Evonik Nutrition \& Care GmbH, Germany). For each $T F$, the ranking (Rank), $P$ value, false discovery rate (FDR), the overlapping genes among the DEG list, and the predicted state (i.e. impact and flux value) calculated using the rationale underlying the Dynamic Impact Approach (DIA) analysis are reported.

Additional File 4:. Extended discussion on methionine synthase (MTR) and cystathionine beta-synthase (CBS) activity, phosphatidylcholine (PC) and very low density lipoproteins (VLDL), and on single genes involved in immune status in MET calves.

Additional File 5: KEGG pathways in 'Lipid Metabolism', 'Amino Acid Metabolism', and 'Immune System' subcategories resulting from the DIA analysis of RNAseq data from liver tissue of 4-d old Holstein calves ( $n=6 /$ group) born to cows randomly assigned to receive a basal control (CON) diet from $-28 \pm 2 \mathrm{~d}$ to parturition [1.47 Mcal/kg dry matter (DM) and $15.3 \%$ crude protein (CP)] with no added Met or CON plus ethyl cellulose Met (MET, Mepron ${ }^{\oplus}$, Evonik Nutrition \& Care GmbH, Germany). The columns represent the effect (impact) and flux responses. The blue bars represent the effect value (0 to 300), and the flux columns represent negative $(-)$ and positive $(+)$ flux $(-300$ to +300$)$ based on the direction of the effect. The positive flux (red bars) indicates an upregulation in treated (MET) liver tissue cells compared to control (CON) ones, while the negative flux (green bars) indicates a downregulation.

Additional File 6:. Ingredient and nutrient composition of far-off (from -45 to $-29 \mathrm{~d}$ ) and close-up (from $-28 \mathrm{~d}$ to parturition) diets fed to Holstein cows used in the present study.

Additional File 7:. Extended information about quantitative real-time PCR. Accession number, gene symbol, and forward and reverse primer sequences of genes analyzed in calf liver.

Additional File 8:. Gene/pathway-based network visualization obtained with Pathway Network Visualizer (PANEV) tool, considering the entire list of differentially expressed genes (FDR $\leq 0.10$ ). The network was created taking into account the main pathways of interest involved in 'Glycolysis/ gluconeogenesis', 'Lipid metabolism', 'Amino acid metabolism' and 'Immune system', along with the list of their interconnected (i.e. up- and downstream) pathways based on information retrieved on KEGG pathway database.

Additional File 9:. Transcription Factor/Gene/pathway-based network visualization matching the outcomes from Pathway Network Visualizer (PANEV) tool with the main results obtained by ChIP-X Enrichment Analysis 3 (ChEA3) software.

\section{Acknowledgements}

AA was supported by a fellowship from King Saud University (Riyadh, Saudi Arabia) to perform his PhD studies at the University of Illinois (Urbana). FB was supported by a fellowship from Coordenação de Aperfeiçoamento de 
Pessoal de Nível Superior (CAPES; Brazil) and National Institute of Food and Agriculture (Grant: ILLU-538-914) to perform her PhD studies at University of Illinois (Urbana).

\section{Authors' contributions}

VP performed statistical analyses and wrote the main draft of the manuscript. MD contributed to writing the manuscript. AA and FB performed the cow and calf study, harvested samples, and performed enzyme activity and molecular assays. ET contributed reagents and tools and performed the plasma assays. CP, JG and JJL designed the cow and calf study. All authors read and approved the final manuscript.

\section{Funding}

Evonik Nutrition \& Care GmbH had a role in the study design and provided financial support to cover costs of animal use, data collection, and sample analysis.

\section{Availability of data and materials}

The raw sequencing data of 12 animals in this study are available from the GEO site of NCBI under accession number GSE163644.

\section{Declarations}

\section{Ethics approval and consent to participate}

All procedures for this study were conducted in accordance with a protocol approved by the Institutional Animal Care and Use Committee (IACUC) of the University of Illinois (protocol \# 14270).

\section{Consent for publication}

Not applicable.

\section{Competing interests}

$V P, M D, A A, F B, E T$, and $J J L$ declare that they have no competing interests. $\mathrm{CP}$ and $\mathrm{JG}$ are employees of Evonik Nutrition \& Care $\mathrm{GmbH}$. This does not alter the authors' adherence to BMC Genomics policies on sharing data and materials.

\section{Author details}

'Dipartimento Agricoltura, Ambiente e Alimenti, Università degli Studi del Molise, via De Sanctis snc, 86100 Campobasso, Italy. ${ }^{2}$ Department of Animal Sciences and Division of Nutritional Sciences, University of Illinois, Urbana, IL 61801, USA. ${ }^{3}$ Department of Animal Production, College of Food and Agriculture Sciences, King Saud University, Riyadh 11451, Saudi Arabia. ${ }^{4}$ Department of Animal, Dairy and Veterinary Sciences, Utah State University, Logan, UT 84322, USA. ${ }^{5}$ Evonik Operations GmbH, Hanau-Wolfgang, 63457 Essen, Germany. ${ }^{6}$ Department of Animal Sciences, Food and Nutrition (DIAN A), Università Cattolica del Sacro Cuore, 29122 Piacenza, Italy.

\section{Received: 23 December 2020 Accepted: 11 March 2021}

\section{Published online: 17 April 2021}

\section{References}

1. Symonds ME, Sebert SP, Budge H. Nutritional regulation of fetal growth and implications for productive life in ruminants. Animal. 2010:4:1075-83.

2. Bhutta ZA, Das JK, Rizvi A, Gaffey MF, Walker N, Horton S, et al. Evidencebased interventions for improvement of maternal and child nutrition: what can be done and at what cost? Lancet. 2013;382:452-77.

3. Ling T, Hernandez-Jover M, Sordillo LM, Abuelo A. Maternal late-gestation metabolic stress is associated with changes in immune and metabolic responses of dairy calves. J Dairy Sci. 2018;101:6568-80.

4. Hill TM, Bateman HG, Aldrich JM, Schlotterbeck RL, Tanan KG. Optimal concentrations of lysine, methionine, and threonine in milk replacers for calves less than five weeks of age. J Dairy Sci. 2008:91:2433-42.

5. Schwab CG, Broderick GA. A 100-Year Review: Protein and amino acid nutrition in dairy cows. J Dairy Sci. 2017;100:10094-112.

6. Kalhan SC, Marczewski SE. Methionine, homocysteine, one carbon metabolism and fetal growth. Rev Endocr Metab Disord. 2012;13:109-19.

7. McKee SE, Reyes TM. Effect of supplementation with methyl-donor nutrients on neurodevelopment and cognition: considerations for future research. Nutr Rev. 2018;76:497-511.
8. Atmaca G. Antioxidant effects of sulfur-containing amino acids. Yonsei Med J. 2004:45:776-88

9. Coleman DN, Lopreiato V, Alharthi A, Loor JJ. Amino acids and the regulation of oxidative stress and immune function in dairy cattle. J Anim Sci. 2020;98(Supplement_1):S175-93.

10. Jacometo CB, Zhou Z, Luchini D, Corrêa MN, Loor JJ. Maternal supplementation with rumen-protected methionine increases prepartal plasma methionine concentration and alters hepatic mRNA abundance of 1-carbon, methionine, and transsulfuration pathways in neonatal Holstein calves. J Dairy Sci. 2017;100:3209-19.

11. Jin Z, Liu Y. DNA methylation in human diseases. Genes Dis. 2018;5:1-8.

12. Reynolds LP, Borowicz PP, Caton JS, Crouse MS, Dahlen CR, Ward AK. Developmental programming of fetal growth and development. Vet Clin Food Anim Pract. 2019;35:229-47.

13. Cai D, Jia Y, Song H, Sui S, Lu J, Jiang $Z$, et al. Betaine supplementation in maternal diet modulates the epigenetic regulation of hepatic gluconeogenic genes in neonatal piglets. PLoS One. 2014:9:e105504.

14. O'Neill RJ, Vrana PB, Rosenfeld CS. Maternal methyl supplemented diets and effects on offspring health. Front Genet. 2014;5. https://doi.org/10.3389/ fgene.2014.00289.

15. Sookoian S, Gianotti TF, Burgueño AL, Pirola CJ. Fetal metabolic programming and epigenetic modifications: a systems biology approach. Pediatr Res. 2013;73:531-42.

16. Zhu Z, Cao F, Li X. Epigenetic programming and fetal metabolic programming. Front Endocrinol. 2019;10. https://doi.org/10.3389/fendo.2019. 00764.

17. Barker DJ. In utero programming of chronic disease. Clin Sci. 1998;95:11528.

18. Barker DJ. In utero programming of cardiovascular disease. Theriogenology. 2000:53:555-74.

19. Godfrey KM, Barker DJ. Fetal programming and adult health. Public Health Nutr. 2001:4:611-24.

20. Papas AM, Vicini JL, Clark JH, Peirce-Sandner S. Effect of rumen-protected methionine on plasma free amino acids and production by dairy cows. J Nutr. 1984;114:2221-7.

21. Wang C, Liu HY, Wang YM, Yang ZQ, Liu JX, Wu YM, et al. Effects of dietary supplementation of methionine and lysine on milk production and nitrogen utilization in dairy cows. J Dairy Sci. 2010;93:3661-70.

22. Coleman DN, Alharthi AS, Liang Y, Lopes MG, Lopreiato V, Vailati-Riboni M, et al. Multifaceted role of one-carbon metabolism on immunometabolic control and growth during pregnancy, lactation and the neonatal period in dairy cattle. J Anim Sci Biotechnol. 2021;12:27.

23. Zhou Z, Vailati-Riboni M, Trevisi E, Drackley JK, Luchini DN, Loor JJ. Better postpartal performance in dairy cows supplemented with rumen-protected methionine compared with choline during the peripartal period. J Dairy Sci. 2016:99:8716-32.

24. Batistel F, Arroyo JM, Bellingeri A, Wang L, Saremi B, Parys C, et al. Ethylcellulose rumen-protected methionine enhances performance during the periparturient period and early lactation in Holstein dairy cows. J Dairy Sci. 2017; 100:7455-67

25. Batistel F, Alharthi AS, Wang L, Parys C, Pan Y-X, Cardoso FC, et al. Placentome nutrient transporters and mammalian target of rapamycin signaling proteins are altered by the methionine supply during late gestation in dairy cows and are associated with newborn birth weight. $J$ Nutr. 2017:147:1640-7.

26. Alharthi AS, Coleman DN, Liang Y, Batistel F, Elolimy AA, Yambao RC, et al Hepatic 1-carbon metabolism enzyme activity, intermediate metabolites, and growth in neonatal Holstein dairy calves are altered by maternal supply of methionine during late pregnancy. J Dairy Sci. 2019;102:10291-303.

27. Alharthi AS, Batistel F, Abdelmegeid MK, Lascano G, Parys C, Helmbrecht A, et al. Maternal supply of methionine during late-pregnancy enhances rate of Holstein calf development in utero and postnatal growth to a greater extent than colostrum source. J Anim Sci Biotechnol. 2018;9:83.

28. Li P, Yin Y-L, Li D, Kim SW, WU G. Amino acids and immune function. Br J Nutr. 2007:98:237-52.

29. Lopes MG, Alharthi AS, Lopreiato V, Abdel-Hamied E, Liang Y, Coleman DN, et al. Maternal body condition influences neonatal calf whole-blood innate immune molecular responses to ex vivo lipopolysaccharide challenge. J Dairy Sci. 2021;104:2266-79.

30. Jacometo CB, Zhou Z, Luchini D, Trevisi E, Corrêa MN, Loor JJ. Maternal rumen-protected methionine supplementation and its effect on blood and 
liver biomarkers of energy metabolism, inflammation, and oxidative stress in neonatal Holstein calves. J Dairy Sci. 2016;99:6753-63.

31. Jacometo CB, Alharthi AS, Zhou Z, Luchini D, Loor JJ. Maternal supply of methionine during late pregnancy is associated with changes in immune function and abundance of microRNA and mRNA in Holstein calf polymorphonuclear leukocytes. J Dairy Sci. 2018;101:8146-58.

32. Peñagaricano F, Souza AH, Carvalho PD, Driver AM, Gambra R, Kropp J, et al. Effect of maternal methionine supplementation on the transcriptome of bovine preimplantation embryos. PLoS One. 2013;8:e72302.

33. Hulbert LE, Moisá SJ. Stress, immunity, and the management of calves. J Dairy Sci. 2016;99:3199-216.

34. Zhou Z, Bulgari O, Vailati-Riboni M, Trevisi E, Ballou MA, Cardoso FC, et al. Rumen-protected methionine compared with rumen-protected choline improves immunometabolic status in dairy cows during the peripartal period. J Dairy Sci. 2016;99:8956-69.

35. Osorio JS, Trevisi E, Ji P, Drackley JK, Luchini D, Bertoni G, et al. Biomarkers of inflammation, metabolism, and oxidative stress in blood, liver, and milk reveal a better immunometabolic status in peripartal cows supplemented with Smartamine M or MetaSmart. J Dairy Sci. 2014;97:7437-50.

36. Mato JM, Martínez-Chantar ML. Lu SC. Methionine metabolism and liver disease. Annu Rev Nutr. 2008;28:273-93.

37. Lu SC. S-Adenosylmethionine. Int J Biochem Cell Biol. 2000;32:391-5.

38. Maddocks ODK, Labuschagne CF, Adams PD, Vousden KH. Serine metabolism supports the methionine cycle and DNA/RNA methylation through de novo ATP synthesis in cancer cells. Mol Cell. 2016;61:210-21.

39. Ducker GS, Rabinowitz JD. One-carbon metabolism in health and disease. Cell Metab. 2017;25:27-42.

40. Mosharov E, Cranford MR, Banerjee R. The quantitatively important relationship between homocysteine metabolism and glutathione synthesis by the transsulfuration pathway and its regulation by redox changes. Biochemistry. 2000;39:13005-11.

41. Sanderson SM, Gao X, Dai Z, Locasale JW. Methionine metabolism in health and cancer: a nexus of diet and precision medicine. Nat Rev Cancer. 2019; 19:625-37.

42. Niculescu MD, Zeisel SH. Diet, methyl donors and DNA methylation: interactions between dietary folate, methionine and choline. J Nutr. 2002; 132(8 Suppl):2333S-5S.

43. Sinclair KD, Allegrucci C, Singh R, Gardner DS, Sebastian S, Bispham J, et al. DNA methylation, insulin resistance, and blood pressure in offspring determined by maternal periconceptional B vitamin and methionine status. Proc Natl Acad Sci USA. 2007;104:19351-6.

44. Serefidou M, Venkatasubramani $A V$, Imhof $A$. The impact of one carbon metabolism on histone methylation. Front Genet. 2019;10. https://doi.org/1 0.3389/fgene.2019.00764

45. Hayashi T, Teruya T, Chaleckis R, Morigasaki S, Yanagida M. Sadenosylmethionine synthetase is required for cell growth, maintenance of $\mathrm{GO}$ phase, and termination of quiescence in fission yeast. iscience. 2018;5:38-51.

46. Kudo NR, Anger M, Peters AHFM, Stemmann O, Theussl H-C, Helmhart W, et al. Role of cleavage by separase of the Rec8 kleisin subunit of cohesin during mammalian meiosis I. J Cell Sci. 2009;122:2686-98.

47. Li J, Qian W-P, Sun Q-Y. Cyclins regulating oocyte meiotic cell cycle progression. Biol Reprod. 2019;101:878-81.

48. An Q, Sun H, Zhang J, Lu Z, Peng W, Xu S, et al. Methionine adenosyltransferase $2 \beta$ participates in mouse oocyte maturation by regulating the MAPK pathway. Reprod Sci. 2020:27:163-71.

49. Kuroda A, Rauch TA, Todorov I, Ku HT, Al-Abdullah IH, Kandeel F, et al. Insulin Gene Expression Is Regulated by DNA Methylation. PLoS One. 2009; 4. https://doi.org/10.1371/journal.pone.0006953.

50. Zachut M, Honig H, Striem S, Zick Y, Boura-Halfon S, Moallem U. Periparturient dairy cows do not exhibit hepatic insulin resistance, yet adipose-specific insulin resistance occurs in cows prone to high weight loss. J Dairy Sci. 2013;96:5656-69.

51. Rico JE, Myers WA, Laub DJ, Davis AN, Zeng Q, McFadden JW. Hot topic: Ceramide inhibits insulin sensitivity in primary bovine adipocytes. J Dairy Sci. 2018;101:3428-32.

52. Yabe D, Brown MS, Goldstein JL. Insig-2, a second endoplasmic reticulum protein that binds SCAP and blocks export of sterol regulatory elementbinding proteins. Proc Natl Acad Sci U S A. 2002;99:12753-8.

53. Zhang HH, Lipovsky Al, Dibble CC, Sahin M, Manning BD. S6K1 regulates GSK3 under conditions of mTOR-dependent feedback inhibition of Akt. Mol Cell. 2006;24:185-97.
54. Shimura T, Kakuda S, Ochiai Y, Nakagawa H, Kuwahara Y, Takai Y, et al. Acquired radioresistance of human tumor cells by DNA-PK/AKT/GSK3Bmediated cyclin D1 overexpression. Oncogene. 2010;29:4826-37.

55. Arai T, Kano F, Murata M. Translocation of forkhead box $\mathrm{O} 1$ to the nuclear periphery induces histone modifications that regulate transcriptional repression of PCK1 in HepG2 cells. Genes Cells. 2015;20:340-57.

56. Girard J. Metabolic adaptations to change of nutrition at birth. Biol Neonate. 1990;58(Suppl 1):3-15.

57. Hammon HM, Steinhoff-Wagner J, Schönhusen U, Metges CC, Blum JW. Energy metabolism in the newborn farm animal with emphasis on the calf: endocrine changes and responses to milk-born and systemic hormones. Domestic Anim Endocrinol. 2012;43:171-85.

58. Steinhoff-Wagner J, Görs S, Junghans P, Bruckmaier RM, Kanitz E, Metges $C C$, et al. Maturation of endogenous glucose production in preterm and term calves1. J Dairy Sci. 2011;94:5111-23.

59. van Schaftingen E, Gerin I. The glucose-6-phosphatase system. Biochem J. 2002:362(Pt 3):513-32.

60. Gatfield D, Schibler U. Circadian glucose homeostasis requires compensatory interference between brain and liver clocks. Proc Natl Acad Sci U S A. 2008;105:14753-4.

61. Lee J-M, Seo W-Y, Song K-H, Chanda D, Kim YD, Kim D-K, et al. AMPKdependent repression of hepatic gluconeogenesis via disruption of CREB. CRTC2 complex by orphan nuclear receptor small heterodimer partner. J Biol Chem. 2010;285:32182-91.

62. Zhang $X$, Yang S, Chen J, Su Z. Unraveling the regulation of hepatic gluconeogenesis. Front Endocrinol. 2019;9. https://doi.org/10.3389/fendo.2 018.00802 .

63. Wang Y, Inoue H, Ravnskjaer K, Viste K, Miller N, Liu Y, et al. Targeted disruption of the CREB coactivator Crtc2 increases insulin sensitivity. Proc Natl Acad Sci U S A. 2010;107:3087-92.

64. Govindan MV, Seguin C. Final steps in the feedback regulation of human glucocorticoid receptor gene and role of nuclear protein phosphatase $2 \mathrm{~A}$. Mol Biol Genet Eng. 2013;1:2.

65. Mueller KM, Themanns M, Friedbichler K, Kornfeld J-W, Esterbauer H, Tuckermann JP, et al. Hepatic growth hormone and glucocorticoid receptor signaling in body growth, steatosis and metabolic liver cancer development. Mol Cell Endocrinol. 2012;361:1-11.

66. Schlegel G, Keller J, Hirche F, Geißler S, Schwarz FJ, Ringseis R, et al. Expression of genes involved in hepatic carnitine synthesis and uptake in dairy cows in the transition period and at different stages of lactation. BMC Vet Res. 2012;8:28

67. Jump DB, Botolin D, Wang Y, Xu J, Christian B, Demeure O. Fatty acid regulation of hepatic gene transcription. J Nutr. 2005;135:2503-6.

68. Rosenbaum S, Ringseis R, Most E, Hillen S, Becker S, Erhardt G, et al. Genes involved in carnitine synthesis and carnitine uptake are up-regulated in the liver of sows during lactation. Acta Vet Scand. 2013;55:24.

69. Karlic H, Lohninger S, Koeck T, Lohninger A. Dietary I-carnitine stimulates carnitine acyltransferases in the liver of aged rats. J Histochem Cytochem. 2002:50:205-12.

70. Longo N, Frigeni M, Pasquali M. Carnitine transport and fatty acid oxidation. Biochim Biophys Acta (BBA). 2016;1863:2422-35.

71. Zhang L, Joshi AK, Smith S. Cloning, expression, characterization, and interaction of two components of a human mitochondrial fatty acid synthase. Malonyltransferase and acyl carrier protein. J Biol Chem. 2003;278: 40067-74.

72. Kremer L, Nampoothiri KM, Lesjean S, Dover LG, Graham S, Betts J, et al. Biochemical characterization of acyl carrier protein (AcpM) and malonylCoA:AcpM transacylase (mtFabD), two major components of Mycobacterium tuberculosis fatty acid synthase II. J Biol Chem. 2001;276:27967-74.

73. Hodson L. Hepatic fatty acid synthesis and partitioning: the effect of metabolic and nutritional state. Proceed Nutr Soc. 2019;78:126-34.

74. Foster DW. Malonyl-CoA: the regulator of fatty acid synthesis and oxidation. J Clin Invest. 2012;122:1958-9.

75. Auboiron S, Durand D, Bauchart D, Robert JC, Chapman MJ. Lipoprotein metabolism in the preruminant calf: effect of a high fat diet supplemented with L-methionine. J Dairy Sci. 1994;77:1870-81.

76. García-Trevijano ER, Latasa MU, Carretero MV, Berasain C, Mato JM, Avila MA. S-adenosylmethionine regulates MAT1A and MAT2A gene expression in cultured rat hepatocytes: a new role for Sadenosylmethionine in the maintenance of the differentiated status of the liver. FASEB J. 2000;14:2511-8. 
77. Martinov MV, Vitvitsky VM, Banerjee R, Ataullakhanov FI. The logic of the hepatic methionine metabolic cycle. Biochim Biophys Acta (BBA). 2010;1804: 89-96.

78. Fernández-Arroyo S, Cuyàs E, Bosch-Barrera J, Alarcón T, Joven J, Menendez $J A$. Activation of the methylation cycle in cells reprogrammed into a stem cell-like state. Oncoscience. 2016;2:958-67.

79. Loor JJ, Bionaz M, Drackley JK. Systems physiology in dairy cattle: nutritional genomics and beyond. Annu Rev Anim Biosci. 2013;1:365-92.

80. Jia H, Li X, Liu G, Loor JJ, Bucktrout R, Sun X, et al. Perilipin 5 promotes hepatic steatosis in dairy cows through increasing lipid synthesis and decreasing very low density lipoprotein assembly. J Dairy Sci. 2019;102:83345.

81. Pinotti L, Baldi A, Dell'Orto V. Comparative mammalian choline metabolism with emphasis on the high-yielding dairy cow. Nutr Res Rev. 2002;15:31532.

82. Schaeffer L, Gohlke H, Müller M, Heid IM, Palmer LJ, Kompauer I, et al. Common genetic variants of the FADS1 FADS2 gene cluster and their reconstructed haplotypes are associated with the fatty acid composition in phospholipids. Hum Mol Genet. 2006;15:1745-56.

83. Dushianthan A, Cusack R, Grocott MPW, Postle AD. Abnormal liver phosphatidylcholine synthesis revealed in patients with acute respiratory distress syndrome. J Lipid Res. 2018;59:1034-45.

84. Ridgway ND, Vance DE. Specificity of rat hepatic phosphatidylethanolamine $\mathrm{N}$-methyltransferase for molecular species of diacyl phosphatidylethanolamine. J Biol Chem. 1988;263:16856-63.

85. DeLong CJ, Shen YJ, Thomas MJ, Cui Z. Molecular distinction of phosphatidylcholine synthesis between the CDP-choline pathway and phosphatidylethanolamine methylation pathway. J Biol Chem. 1999;274 29683-8.

86. Devlin AM, Singh R, Wade RE, Innis SM, Bottiglieri T, Lentz SR. Hypermethylation of Fads2 and altered hepatic fatty acid and phospholipid metabolism in mice with hyperhomocysteinemia. J Biol Chem. 2007;282: 37082-90.

87. Nair KS, Short KR. Hormonal and signaling role of branched-chain amino acids. J Nutr. 2005;135:1547S-52S.

88. Jose DG, Good RA. Quantitative effects of nutritional essential amino acid deficiency upon immune responses to tumors in mice. J Exp Med. 1973;137: $1-9$

89. Petro TM, Bhattacharjee JK. Effect of dietary essential amino acid limitations upon the susceptibility to Salmonella typhimurium and the effect upon humoral and cellular immune responses in mice. Infect Immun. 1981;32: 251-9.

90. Tsukishiro T, Shimizu Y, Higuchi K, Watanabe A. Effect of branched-chain amino acids on the composition and cytolytic activity of liver-associated lymphocytes in rats. J Gastroenterol Hepatol. 2000;15:849-59.

91. Bassit RA, Sawada LA, Bacurau RFP, Navarro F, Martins E, Santos RVT, et al. Branched-chain amino acid supplementation and the immune response of long-distance athletes. Nutrition. 2002;18:376-9.

92. Dong X, Zhou Z, Saremi B, Helmbrecht A, Wang Z, Loor JJ. Varying the ratio of Lys:Met while maintaining the ratios of Thr:Phe, Lys:Thr, Lys:His, and Lys: Val alters mammary cellular metabolites, mammalian target of rapamycin signaling, and gene transcription. J Dairy Sci. 2018;101:1708-18.

93. Nan X, Bu D, Li X, Wang J, Wei H, Hu H, et al. Ratio of lysine to methionine alters expression of genes involved in milk protein transcription and translation and mTOR phosphorylation in bovine mammary cells. Physio Genomics. 2014;46:268-75

94. Ma YF, Batistel F, Xu TL, Han LQ, Bucktrout R, Liang Y, et al. Phosphorylation of AKT serine/threonine kinase and abundance of milk protein synthesis gene networks in mammary tissue in response to supply of methionine in periparturient Holstein cows. J Dairy Sci. 2019;102:4264-74.

95. Graber TG, Borack MS, Reidy PT, Volpi E, Rasmussen BB. Essential amino acid ingestion alters expression of genes associated with amino acid sensing, transport, and mTORC1 regulation in human skeletal muscle. Nutr Metab. 2017; 14:35.

96. Kim J, Guan K-L. mTOR as a central hub of nutrient signalling and cell growth. Nat Cell Biol. 2019;21:63-71.

97. Dufner A, Thomas G. Ribosomal S6 kinase signaling and the control of translation. Exp Cell Res. 1999:253:100-9.

98. Showkat M, Beigh MA, Andrabi Kl. mTOR signaling in protein translation regulation: implications in cancer genesis and therapeutic interventions. Mol Biol Int. 2014:686984
99. Brosnan JT, Brosnan ME. The sulfur-containing amino acids: an Overview. J Nutr. 2006;136:1636S-40S

100. Sun F, Cao Y, Cai C, Li S, Yu C, Yao J. Regulation of nutritional metabolism in transition dairy cows: energy homeostasis and health in response to postruminal choline and methionine. PLOS ONE. 2016;11:e0160659.

101. Abdelmegeid MK, Vailati-Riboni M, Alharthi A, Batistel F, Loor JJ. Supplemental methionine, choline, or taurine alter in vitro gene network expression of polymorphonuclear leukocytes from neonatal Holstein calves. J Dairy Sci. 2017;100:3155-65.

102. Matés JM, Pérez-Gómez C, Núñez de Castro I. Antioxidant enzymes and human diseases. Clin Biochem. 1999;32:595-603.

103. Li S, Tan H-Y, Wang N, Zhang Z-J, Lao L, Wong C-W, et al. The role of oxidative stress and antioxidants in liver diseases. Int J Mol Sci. 2015;16: 26087-124.

104. Hamelet J, Seltzer V, Petit E, Noll C, Andreau K, Delabar JM, et al. Cystathionine beta synthase deficiency induces catalase-mediated hydrogen peroxide detoxification in mice liver. Biochim Biophys Acta (BBA). 2008;1782: $482-8$.

105. Lee H-O, Wang L, Kuo Y-M, Gupta S, Slifker MJ, Li Y, et al. Lack of global epigenetic methylation defects in CBS deficient mice. J Inherit Metab Dis. 2017:40:113-20.

106. Zhou Z, Vailati-Riboni M, Luchini DN, Loor JJ. Methionine and choline supply during the periparturient period alter plasma amino acid and onecarbon metabolism profiles to various extents: potential role in hepatic metabolism and antioxidant status. Nutrients. 2016:9.

107. Batistel F, Arroyo JM, Garces CIM, Trevisi E, Parys C, Ballou MA, et al. Ethylcellulose rumen-protected methionine alleviates inflammation and oxidative stress and improves neutrophil function during the periparturient period and early lactation in Holstein dairy cows. J Dairy Sci. 2018;101:480-90.

108. Ochoa JJ, Ramirez-Tortosa MC, Quiles JL, Palomino N, Robles R, Mataix J, et al. Oxidative stress in erythrocytes from premature and full-term infants during their first $72 \mathrm{~h}$ of life. Free Radic Res. 2003;37:317-22.

109. Gaál T, Ribiczeyné-Szabó P, Stadler K, Jakus J, Reiczigel J, Kövér P, et al. Free radicals, lipid peroxidation and the antioxidant system in the blood of cows and newborn calves around calving. Comp Biochem Physiol Part B. 2006; 143:391-6.

110. Chen Z, Tian R, She Z, Cai J, Li H. Role of oxidative stress in the pathogenesis of nonalcoholic fatty liver disease. Free Rad Biol Med. 2020; 152:116-41.

111. Bieging KT, Mello SS, Attardi LD. Unravelling mechanisms of p53-mediated tumour suppression. Nat Rev Cancer. 2014;14:359-70.

112. Johnson TM, Yu ZX, Ferrans VJ, Lowenstein RA, Finkel T. Reactive oxygen species are downstream mediators of p53-dependent apoptosis. Proc Nat Acad Sci U S A. 1996;93:11848-52.

113. Kim KS, Doss HM, Kim H-J, Yang H-I. Taurine stimulates thermoregulatory genes in brown fat tissue and muscle without an influence on inguinal white fat tissue in a high-fat fiet-induced obese mouse model. Foods. 2020; 9. https://doi.org/10.3390/foods9060688.

114. Abumrad NA. The liver as a hub in thermogenesis. Cell Metab. 2017;26:4545.

115. Vermorel M, Dardillat C, Vernet J, Null S, Demigne C. Energy metabolism and thermoregulation in the newborn calf. Ann Rech Vet. 1983;14:382-9.

116. Chase CCL, Hurley DJ, Reber AJ. Neonatal immune development in the calf and its impact on vaccine response. Vet Clin North Am Food Anim Pract. 2008;24:87-104.

117. Mugnier A, Pecceu K, Schelcher F, Corbiere F. A parallel evaluation of 5 indirect cost-effective methods for assessing failure of passive immunity transfer in neonatal calves. JDS Commun. 2020;1:10-4.

118. Tiegs G, Lohse AW. Immune tolerance: What is unique about the liver. J Autoimmunity. 2010;34:1-6.

119. Kubes $P$, Jenne C. Immune Responses in the Liver. Annu Rev Immunol. 2018:36:247-77.

120. Kingeter LM, Lin X. C-type lectin receptor-induced NF-KB activation in innate immune and inflammatory responses. Cell Mol Immunol. 2012;9:105-12.

121. Tian Z, Chen Y, Gao B. Natural killer cells in liver disease. Hepatology. 2013; 57:1654-62

122. del Fresno C, Iborra S, Saz-Leal P, Martínez-López M, Sancho D. Flexible signaling of myeloid C-type lectin receptors in immunity and inflammation. Front Immunol. 2018;9. https://doi.org/10.3389/fimmu.2018.00804.

123. Li Z, Diehl AM. Innate immunity in the liver. Curr Opin Gastroenterol. 2003; 19:565-71. 
124. Mikulak J, Bruni E, Oriolo F, Di Vito C, Mavilio D. Hepatic natural killer cells: organ-dpecific sentinels of liver Immune homeostasis and physiopathology. Front Immunol. 2019;10. https://doi.org/10.3389/fimmu.2019.00946.

125. Vivier E, Raulet DH, Moretta A, Caligiuri MA, Zitvogel L, Lanier LL, et al. Innate or adaptive immunity? The example of natural killer cells. Science. 2011;331:44-9.

126. Crome SQ, Lang PA, Lang KS, Ohashi PS. Natural killer cells regulate diverse T cell responses. Trends Immunol. 2013;34:342-9.

127. Peng H, Wisse $E$, Tian Z. Liver natural killer cells: subsets and roles in liver immunity. Cell Mol Immunol. 2016;13:328-36.

128. Li T-H, Liu L, Hou Y-Y, Shen S-N, Wang T-T. C-type lectin receptor-mediated immune recognition and response of the microbiota in the gut. Gastroenterol Rep (Oxf). 2019;7:312-21.

129. Geijtenbeek TBH, Gringhuis SI. Signalling through C-type lectin receptors: shaping immune responses. Nat Rev Immunol. 2009:9:465-79.

130. Brown GD, Willment JA, Whitehead L. C-type lectins in immunity and homeostasis. Nat Rev Immunol. 2018;18:374-89.

131. Pereira MS, Alves I, Vicente M, Campar A, Silva MC, Padrão NA, et al. Glycans as key checkpoints of T cell activity and function. Front Immunol. 2018;9. https://doi.org/10.3389/fimmu.2018.02754.

132. Taylor ME, Drickamer K, Schnaar RL, Etzler ME, Varki A. Discovery and classification of glycan-binding proteins. In: Varki A, Cummings RD, Esko JD, Stanley P, Hart GW, Aebi M, et al., editors. Essentials of Glycobiology. 3rd ed. Cold Spring Harbor: Cold Spring Harbor Laboratory Press; 2015. https:// www.ncbi.n/m.nih.gov/books/NBK453061/. Accessed 12 Aug 2020.

133. Kagan JC, Iwasaki A. The phagosome as the organelle linking innate and adaptive immunity. Traffic. 2012;13:1053-61.

134. Lambert MP. Platelets in liver and renal disease. Hematol Am Soc Hematol Educ Program. 2016:251-5.

135. Diggs LP, Greten TF. The effects of platelet accumulation in fatty liver disease. Nat Rev Gastroenterol Hepatol. 2019;16:393-4.

136. Ramadori P, Klag T, Malek NP, Heikenwalder M. Platelets in chronic liver disease, from bench to bedside. JHEP Rep. 2019;1:448-59.

137. Uhlar CM, Burgess CJ, Sharp PM, Whitehead AS. Evolution of the serum amyloid A (SAA) protein superfamily. Genomics. 1994;19:228-35.

138. Meek RL, Eriksen N, Benditt EP. Murine serum amyloid A3 is a high density apolipoprotein and is secreted by macrophages. Proc Natl Acad Sci U S A. 1992;89:7949-52.

139. Uhlar CM, Whitehead AS. Serum amyloid A, the major vertebrate acutephase reactant. Eur J Biochem. 1999:265:501-23.

140. Sander LE, Sackett SD, Dierssen U, Beraza N, Linke RP, Müller M, et al. Hepatic acute-phase proteins control innate immune responses during infection by promoting myeloid-derived suppressor cell function. J Exp Med. 2010;207:1453-64.

141. McDonald TL, Larson MA, Mack DR, Weber A. Elevated extrahepatic expression and secretion of mammary-associated serum amyloid A 3 (MSAA3) into colostrum. Vet Immunol Immunopathol. 2001:83:203-11.

142. Keenan AB, Torre D, Lachmann A, Leong AK, Wojciechowicz ML, Utti V, et al. ChEA3: transcription factor enrichment analysis by orthogonal omics integration. Nucleic Acids Res. 2019;47:W212-24.

143. Bionaz M, Periasamy K, Rodriguez-Zas SL, Hurley WL, Loor JJ. A novel dynamic impact approach (DIA) for functional analysis of time-course omics studies: validation using the bovine mammary transcriptome. PLoS One. 2012;7:e32455

144. Lee $\mathrm{S}$, Dong HH. FoxO integration of insulin signaling with glucose and lipid metabolism. J Endocrinol. 2017;233:R67-79.

145. Niswender KD, Morrison CD, Clegg DJ, Olson R, Baskin DG, Myers MG, et al. Insulin activation of phosphatidylinositol 3-kinase in the hypothalamic arcuate nucleus: a key mediator of insulin-induced anorexia. Diabetes. 2003; 52:227-31.

146. Altomonte J, Richter A, Harbaran S, Suriawinata J, Nakae J, Thung SN, et al. Inhibition of Foxol function is associated with improved fasting glycemia in diabetic mice. Am J Physiol-Endocrinol Metab. 2003;285:E718-28.

147. Jeong JY, Jeoung NH, Park K-G, Lee I-K. Transcriptional regulation of pyruvate dehydrogenase kinase. Diab Metab J. 2012;36:328-35.

148. Gopal K, Saleme B, Al Batran R, Aburasayn H, Eshreif A, Ho KL, et al. FoxO1 regulates myocardial glucose oxidation rates via transcriptional control of pyruvate dehydrogenase kinase 4 expression. Am J Physiol Heart Circ Physiol. 2017;313:H479-90.

149. Sparks JD, Dong HH. FoxO1 and hepatic lipid metabolism. Curr Opin Lipidol. 2009;20:217-26.
150. Cabrera-Ortega AA, Feinberg D, Liang Y, Rossa C, Graves DT. The role of forkhead box 1 (FOXO1) in the immune system: dendritic cells, T cells, B cells, and hematopoietic stem cells. Crit Rev Immunol. 2017;37:1-13.

151. John E, Wienecke-Baldacchino A, Liivrand M, Heinäniemi M, Carlberg C, Sinkkonen $\mathrm{L}$. Dataset integration identifies transcriptional regulation of microRNA genes by PPARy in differentiating mouse 3T3-L1 adipocytes. Nucleic Acids Res. 2012;40:4446-60.

152. Leonardi R, Zhang Y-M, Yun M-K, Zhou R, Zeng F-Y, Lin W, et al. Modulation of pantothenate kinase 3 activity by small molecules that interact with the substrate/allosteric regulatory domain. Chem Biol. 2010;17:892-902.

153. Leonardi R, Zhang Y-M, Rock CO, Jackowski S, Coenzyme A. Back in action. Progress Lipid Res. 2005;44:125-53.

154. Giralt A, Denechaud P-D, Lopez-Mejia IC, Delacuisine B, Blanchet E, Bonner $\mathrm{C}$, et al. E2F1 promotes hepatic gluconeogenesis and contributes to hyperglycemia during diabetes. Mol Metab. 2018;11:104-12.

155. Warg LA, Oakes JL, Burton R, Neidermyer AJ, Rutledge HR, Groshong S, et al. The role of the E2F1 transcription factor in the innate immune response to systemic LPS. Am J Physiol Lung Cell Mol Physiol. 2012;303:L391-400.

156. Herzig S, Hedrick S, Morantte I, Koo S-H, Galimi F, Montminy M. CREB controls hepatic lipid metabolism through nuclear hormone receptor PPARү. Nature. 2003;426:190-3.

157. Wen AY, Sakamoto KM, Miller LS. The role of the transcription factor CREB in immune function. J Immunol. 2010;185:6413-9.

158. Osorio JS, Ji P, Drackley JK, Luchini D, Loor JJ. Supplemental Smartamine M or MetaSmart during the transition period benefits postpartal cow performance and blood neutrophil function. J Dairy Sci. 2013;96:6248-63.

159. Schwab CG. Protected proteins and amino acids for ruminants. In: Biotechnology in Animal Feeds and Animal Feeding. John Wiley \& Sons, Ltd; 1995. p. 115-41. doi:https://doi.org/10.1002/9783527615353.ch7.

160. Overton TR, LaCount DW, Cicela TM, Clark JH. Evaluation of a ruminally protected methionine product for lactating dairy cows. J Dairy Sci. 1996;79: 631-8.

161. Batistel F, Alharthi AS, Yambao RRC, Elolimy AA, Pan Y-X, Parys C, et al. Methionine supply during late-gestation triggers offspring sex-specific divergent changes in metabolic and epigenetic signatures in bovine placenta. J Nutr. 2019;149:6-17.

162. Xu T, Alharthi ASM, Batistel F, Helmbrecht A, Parys C, Trevisi E, et al. Hepatic phosphorylation status of serine/threonine kinase 1, mammalian target of rapamycin signaling proteins, and growth rate in Holstein heifer calves in response to maternal supply of methionine. J Dairy Sci. 2018;101:8476-91.

163. Wu H, Southam AD, Hines A, Viant MR. High-throughput tissue extraction protocol for NMR- and MS-based metabolomics. Anal Biochem. 2008;372: 204-12.

164. Zhou Z, Garrow TA, Dong X, Luchini DN, Loor JJ. Hepatic activity and transcription of betaine-homocysteine methyltransferase, methionine synthase, and cystathionine synthase in periparturient dairy cows are altered to different extents by supply of methionine and choline. J Nutr. 2017;147:11-9.

165. R Core Team. R: a language and environment for statistical computing. Vienna: R Foundation for Statistical Computing; 2018. https://www.R-project. org/

166. Robinson MD, Oshlack A. A scaling normalization method for differential expression analysis of RNA-seq data. Genome Biol. 2010;11:R25

167. Anders S, McCarthy DJ, Chen Y, Okoniewski M, Smyth GK, Huber W, et al. Count-based differential expression analysis of RNA sequencing data using $\mathrm{R}$ and Bioconductor. Nat Protoc. 2013;8:1765-86.

168. Palombo V, Milanesi M, Sferra G, Capomaccio S, Sgorlon S, D'Andrea M. PANEV: an R package for a pathway-based network visualization. BMC Bioinform. 2020:21:1-7.

\section{Publisher's Note}

Springer Nature remains neutral with regard to jurisdictional claims in published maps and institutional affiliations. 